Sadegh et al. 1

\title{
Fezf2 transient expression via modRNA with concurrent SIRT1 inhibition enhances differentiation of cortical subcerebral / corticospinal neuron identity from mES cells
}

5 Authors: Cameron Sadegh ${ }^{1,4}$, Wataru Ebina ${ }^{2}$, Anthony C. Arvanites ${ }^{3}$, Lance S.

6 Davidow $^{3}$, Lee L. Rubin ${ }^{3}$, Jeffrey D. Macklis ${ }^{1,5}$

8 1) Department of Stem Cell and Regenerative Biology, Center for Brain Science, and

9 Harvard Stem Cell Institute, Harvard University, Cambridge, Massachusetts 02138,

10 USA.

11 2) Department of Stem Cell and Regenerative Biology, Harvard University, Cambridge,

12 MA 02138, USA; Program in Cellular and Molecular Medicine, Division of

13 Hematology/Oncology, Boston Children's Hospital, MA 02116, USA.

14 3) Department of Stem Cell and Regenerative Biology, and Harvard Stem Cell Institute,

15 Harvard University, Cambridge, MA 02138, USA

16 4) current address: Department of Neurosurgery, Massachusetts General Hospital and

17 Harvard Medical School, Boston, MA 02114, USA.

5) Corresponding author. Address: Bauer Laboratory 103; Harvard University; 7 Divinity

Avenue; Cambridge, MA 02138; TEL: (617) 495-5413; FAX: (617) 496-9679; Email:

20 jeffrey macklis@harvard.edu 
Sadegh et al. 2

\section{Abstract}

During late embryonic development of the cerebral cortex, the major class of

23 cortical output neurons termed subcerebral projection neurons (SCPN; including the

24 predominant population of corticospinal neurons, CSN) and the class of interhemispheric

25 callosal projection neurons (CPN) initially express overlapping molecular controls that

26 later undergo subtype-specific refinements. Such molecular refinements are largely

27 absent in heterogeneous, maturation-stalled, neocortical-like neurons (termed "cortical"

28 here) spontaneously generated by established embryonic stem cell (ES) and induced

29 pluripotent stem cell (iPSC) differentiation. Building on recently identified central

30 molecular controls over SCPN development, we used a combination of synthetic modified

31 mRNA (modRNA) for Fezf2, the central transcription factor controlling SCPN specification,

32 and small molecule screening to investigate whether distinct chromatin modifiers might

33 complement Fezf2 functions to promote SCPN-specific differentiation by mouse ES

34 (mES)-derived cortical-like neurons. We find that the inhibition of a specific histone

35 deacetylase, Sirtuin 1 (SIRT1), enhances refinement of SCPN subtype molecular identity

36 by both mES-derived cortical-like neurons and primary dissociated E12.5 mouse cortical

37 neurons. In vivo, we identify that SIRT1 is specifically expressed by CPN, but not SCPN,

38 during late embryonic and postnatal differentiation. Together, these data indicate that

39 SIRT1 has neuronal subtype-specific expression in the mouse cortex in vivo, and its

40 inhibition enhances subtype-specific differentiation of highly clinically relevant SCPN /

41 CSN cortical neurons in vitro. 
Sadegh et al. 3

\section{Introduction}

Subcerebral projection neurons (SCPN) are the broad population of cerebral cortex (cortical) neurons that connect and provide high-level descending control via axonal projections from the neocortex (termed "cortical" here) to distal targets in the brainstem (midbrain, hindbrain) and spinal cord (Molyneaux et al., 2007; Woodworth et al., 2012; Custo Greig et al., 2013). The large subtype of SCPN providing descending motor control to the spinal cord (direct or via sensory feedback) are termed corticospinal neurons (CSN), a term often considered to also include cortical neurons projecting to brainstem targets. SCPN are the brain neurons that degenerate in ALS and related motor neuron diseases, and whose injury (in particular, to CSN) is responsible for the loss of voluntary motor function in spinal cord injury (Sances et al., Nat Neurosci. 2016). Early and defining molecular features of SCPN include high-level expression of FEZF2 and CTIP2, required for the specification and control of SCPN molecular, cellular, and anatomical identity (Molyneaux et al., 2005; Arlotta et al., 2005; Chen et al., 2005; Ozdinler and Macklis, 2006; Lai et al., 2008; Chen et al., 2008; Shim et al., 2012; Woodworth et al., 2012; Greig et al., 2013; Woodworth et al., 2016).

Midway through corticogenesis, post-mitotic SCPN identity is initially masked by transient co-expression of regulators of interhemispheric callosal projection neuron (CPN) development, including SATB2 (Alcamo et al., 2008; Britanova et al., 2008; Azim et al., 2009; Woodworth et al., 2012; Sadegh and Macklis, 2014; Leone et al., 2015). At later stages of maturation, SCPN discontinue expression of SATB2, and further resolve into diverse subpopulations of FEZF2- and CTIP2-expressing projection neurons with cortical

4 area- and target-specific molecular identities, properties, and functional circuit 
Sadegh et al. 4

65 connectivity (Woodworth et al., 2012; Custo Greig et al., 2013; Woodworth et al., 2016;

66 Greig et al., 2016; Galazo et al., 2016).

Multiple epigenetic factors support the post-mitotic identity refinement of

68 contrasting cortical neuron subtypes, such as SCPN and CPN, and enable their

69 maturation (Kishi and Macklis, 2004; MacDonald and Roskams, 2008, 2009; Kishi et al.,

70 2012; Yip et al., 2012). For example, SATB2 is a matrix-attachment region (MAR) binding

71 protein (Britanova et al., 2005; Gyorgy et al., 2008; Alcamo et al., 2008; Britanova et al.,

72 2008) that can mediate long-range interactions of enhancer sites with promoters (Yasui

73 et al., 2002; Cai et al., 2003; Dobreva et al., 2003), and, together with SKI, can recruit the

74 nucleosome remodeling and histone deacetylase (NuRD) complex (Baranek et al., 2012).

75 Moreover, the transcription factors CTIP2 and CTIP1 (BCL11B, BCL11A; Leid et al.,

76 2004), which are differentially expressed with subtype-specificity in the cortex, and which

77 regulate the precision of SCPN and CPN differentiation (Arlotta et al., 2005; Lai et al.,

78 2008; Tomassy et al., 2010; Woodworth et al., 2016; Greig et al., 2016), have also been

79 demonstrated to interact with both the NuRD complex (Topark-Ngarm et al., 2006;

80 Cismasiu et al., 2005) and SIRT1 (Senawong et al., 2003; Senawong et al., 2005) to

81 mediate chromatin remodeling in cells outside of the brain. Together, these reports

82 suggest that chromatin remodeling might contribute to post-mitotic refinement of cortical

83 projection neuron subtypes, particularly in refinement of CTIP2-expressing SCPN from

84 SATB2-/CTIP1-expressing CPN.

85 ES/iPSC-based models of cortical differentiation are emerging as useful tools to

86 investigate roles of chromatin modifications in cortical development (Tiberi et al., 2012;

87 Juliandi et al., 2012). While protocols for directing cortical differentiation from ES/iPSC 
Sadegh et al. 5

88 cells in systems ranging from monolayer cultures to organoids have succeeded in 89 replicating some of the molecular characteristics of cortical development (Eiraku et al.,

90 2008; Gaspard et al., 2008; Michelsen et al., 2015; Lancaster et al., 2013, Arlotta, 2018;

91 Pasca, 2018), the mature refinement of cortical subtypes is incomplete with these

92 protocols; immature neurons become "stalled" at an mid-embryonic developmental stage

93 (Sadegh and Macklis, 2014). These data suggest that ES-derived cortical cells are

94 unlikely to have a sufficiently permissive molecular context for the precise refinement of

95 SCPN identity. In vivo, Fezf2 mis-expression in multiple embryonic and early postnatal

96 forebrain progenitor and early post-mitotic neuron populations can redirect their

97 differentiation to SCPN-like identities, suggesting a strategy to potentially circumvent this

98 problem (Molyneaux et al., 2005; Lai et al., 2008; Chen et al., 2008; Rouaux and Arlotta,

99 2010; Rouaux and Arlotta, 2013; De la Rossa et al., 2013). However, Fezf2 is regulated

100 by multiple cofactors, including Sox family transcription factors (Lai et al., 2008; Azim et

101 al., 2009; Shim et al., 2012), and, in the absence of a forebrain-specific molecular context

102 at early stages of ES cell differentiation, Fezf2 mis-expression by ES cells does not drive

103 SCPN molecular identity (Wang et al., 2011; Miskinyte et al., 2018; Sadegh, unpublished 104 data).

ES/iPS cell-derived models of neocortical differentiation necessarily bypass

106 precisely orchestrated, spatiotemporal mechanisms of embryonic differentiation (as

107 demonstrated in the analysis of intermediate states of ES cell-derived spinal motor 108 neurons; Briggs et al., 2017), suggesting that, in contrast to established spinal motor 109 neuron differentiation, additional subtype-specific epigenetic modulation might be 110 required for optimal in vitro generation of diverse neocortical neuron subtypes. 
Sadegh et al. 6

We hypothesized that alteration of the chromatin landscape within incompletely specified mES-derived cortical progenitors might promote a permissive molecular context

113 for Fezf2-directed SCPN subtype refinement. To identify candidate chromatin remodeling 114 enzymes, we conducted a high-content screen of mouse mES-derived cortical cells using 115 a library of small molecules that modulate known epigenetic enzymes. Mature SCPN 116 refinement was assessed by measuring changes in the ratio of positive (CTIP2) and 117 negative (SATB2, CTIP1) markers of SCPN differentiation. This strategy emphasizes the 118 utility of multiple exclusionary markers to delineate SCPN-specific differentiation among 119 mES-derived cortical progenitors, in contrast to the approach of evaluating for multiple 120 positive markers that are often expressed in immature SCPN-like neurons (Sadegh and 121 Macklis, 2014). From this screen, we identify the histone deacetylase Sirtuin1 (SIRT1) as an 123 effective repressor of Fezf2-mediated SCPN molecular refinement. Small molecule 124 inhibitors of SIRT1 (e.g., EX-527, CHIC-35) enhance Fezf2-induced molecular maturation 125 of SCPN by maintaining CTIP2 expression and reducing SATB2 and CTIP1 expression 126 by both mES-derived cortical-like neurons and primary dissociated mouse cortical 127 neurons in vitro. We also identify differential refinement of SIRT1 expression in late 128 embryonic cortical neuron subtypes in vivo: elevated SIRT1 expression by CPN, and 129 diminished expression by SCPN. Together, these data identify chromatin remodeling as 130 an important mechanism of cortical subtype refinement both in vivo and for in vitro 131 directed differentiation, and identify a route to enhanced subtype-specific differentiation 132 of developmentally and clinically important cortical neurons from pluripotent stem cells. 
Sadegh et al. 7

\section{Results}

ModRNA provides dose- and time-dependent protein expression in mES-derived cells

Synthetic modified mRNA (modRNA) enables precision over gene dosage and

137 timing by multiple cell types (Warren et al., 2010). Because modRNA does not integrate

138 into the genome, and has a limited duration of expression ( 2 days), modRNA enables

139 transient gene expression without manipulating the genomes of ES-derived cells. We

140 tested the feasibility of modRNA transfection in feeder-free E14Tg2a mES cells

141 undergoing an established monolayer protocol of differentiation that generates

142 heterogeneous, maturation-limited, neocortical-like neurons (Gaspard et al., 2008;

143 Gaspard et al., 2009; Sadegh and Macklis, 2014).

In agreement with the prior literature, we find a dose-dependent intensity of GFP expression after transfection of mES-derived cells with GFP modRNA. At the peak of

146 pallial-like differentiation at day 14, modRNA-induced GFP expression peaks between

147 12-24 hours, with a sharp reduction of expression by $48 \mathrm{hrs}$ (Figure 1A,B). We also find

148 that modRNA transfection is not biased to a specific neural population; modRNA broadly

149 transfects NESTIN-expressing neural progenitors, TuJ1-expressing immature neurons,

150 and other cells (Figure S1). There is no appreciable change in cell density between

151 conditions, consistent with previously published work (Warren et al., 2010). Importantly,

152 the timing and duration of modRNA expression matches the known kinetics for other

153 proteins and transcription factors (Mandal and Rossi, 2013). These data indicate that

154 modRNA transfection enables dose- and time-dependent gene expression in mES-

155 derived cells, including progenitors and neurons. 
Sadegh et al. 8

157

158

159

160

\section{Transient Fezf2 expression rescues SCPN fate specification in Fezf2\% mice in vivo}

Prior to using Fezf2 encoded modRNA for transient expression in mES-derived neurons, we first tested the functionality of Fezf2 modRNA in mice in vivo, using an established Fezf2 null experimental rescue paradigm. In Fezf2 null mice, SCPN do not develop, and their progenitors are re-specified to CPN (Molyneaux et al., 2005; Chen et al., 2005). However, delivering Fezf2 by in utero plasmid electroporation in Fezf2 null mice at E12.5 (when FEZF2 would normally be expressed at a high level) can rescue SCPN specification and their projections to the distal hindbrain (Azim, 2009). Moreover, at $\mathrm{E} 13.5, \mathrm{E} 15.5$, and later ages, Fezf2 mis-expression by plasmid electroporation can redirect CPN to acquire most critical features of SCPN identity (Molyneaux et al., 2005; Chen et al., 2008; Rouaux and Arlotta, 2010; Rouaux and Arlotta, 2013; De la Rossa et al., 2013).

We hypothesized that, if transient Fezf2 expression delivered by in utero electroporation of a single dose of Fezf2 modRNA in Fezf2 null mice can rescue SCPN differentiation, then a similar approach to modRNA delivery might effectively direct differentiation of ES-derived pallial-like progenitors in vitro. The extent of in utero GFP modRNA electroporation into the pallium (Figure 1C) is largely limited to the mitotic (Ki67expressing) ventricular zone (Figure 1D). In Fezf2 null mice at E12.5, we find that in utero electroporation of Fezf2 modRNA (with tdTomato plasmid for long-term visualization of axons; Figure $\mathbf{1 E}, \mathbf{F}, \mathbf{G}$ ) rescues a subset of SCPN that project beyond the thalamus to the cerebral peduncle (Figure $\mathbf{1 H}, \mathbf{I})$, comparable to similarly timed plasmid-mediated Fezf2 expression using the same, robust in utero electroporation platform (Molyneaux et al., 2005; Arlotta et al., 2005; Chen et al., 2005; Chen et al., 2008; Shim et al., 2012). In 
Sadegh et al. 9

180 contrast, in utero electroporation of Fezf2 modRNA does not induce SCPN specification 181 at E15.5 (data not shown) when progenitors are no longer producing SCPN. These data

182 suggest that a single, transient dose of Fezf2 is sufficient to rescue Fezf2-null SCPN at

$183 \mathrm{E} 12.5$, and that this relatively small dose of Fezf2 modRNA is only functional within the 184 permissive molecular context of E12.5 neocortical progenitors.

Transient Fezf2 expression alone does not significantly promote SCPN differentiation by mES-derived neocortical-like neurons

We next asked whether Fezf2 modRNA alone can induce SCPN-specific differentiation by mES-derived neocortical-like cells (Gaspard et al., 2008; Gaspard et al., 2009; Sadegh and Macklis, 2014). Because these previously established protocols of monolayer differentiation generate limited quantities of mES-derived neocortical neurons,

192 we used randomized, automated imaging (at 20x magnification, on approximately 40 193 fields per well; $\sim 5,000$ cells), to count sufficient numbers of neocortical-like neurons for 194 these analyses. A high threshold for positive antibody labeling was manually established 195 because populations of mES-derived neurons express a continuum of transcription factor 196 labeling intensities, in striking contrast to populations of primary dissociated E15.5 mouse 197 neocortical neurons, which typically display distinct trimodal labeling (negative, low expression, high expression; see Methods for details). Normally, induction of CTIP2 expression occurs within 48 hrs of Fezf2 plasmid expression. However, 48 hrs after Fezf2 200 modRNA transfection in mES-derived neocortical cells at in vitro day 18, the total 201 numbers of either CTIP2- or SATB2-expressing neocortical neurons are not increased 202 (Figure S2A). This result is not surprising given the heterogeneity and immaturity of 
203 neocortical-like neurons in this established protocol of ES cell culture (Sadegh and 204 Macklis, 2014).

We hypothesized that, rather than broadly promoting CTIP2 expression in non-

206 neocortical-like neurons, a transient dose of Fezf2 modRNA might promote SCPN

207 subtype-specific refinement by only a smaller subset of neocortical-like neurons, perhaps

208 those already "poised" to differentiate further into corticofugal neurons. We developed a

209 metric for delineating SCPN identity refinement in this subset of neocortical-like neurons

210 by quantifying the ratio of neurons that have matured and only express CTIP2 to neurons

211 that remain immature and have overlapping expression of CTIP2 and SATB2. Even by

212 this more nuanced metric of SCPN identify refinement, we find that Fezf2 modRNA

213 expression in mES-derived neocortical cells does not, by itself, significantly increase

214 SCPN subtype differentiation (Figure S2A,B; although there is a trend toward increased

215 SCPN). These data indicate that a single, transient dose of Fezf2 expression by mES-

216 derived neurons is not sufficient to refine SCPN identity given the inappropriate molecular

217 context of heterogeneous and maturation-stalled mES-derived neocortical-like neurons

218 (Sadegh and Macklis, 2014), suggesting that additional, potentially complementary

219 manipulations are needed to direct SCPN differentiation.

221 Small molecule screening of mES-derived neocortical-like neurons identifies SIRT1

We next asked whether remodeling the chromatin landscape might enable a higher

223 proportion of neocortical-like neurons to respond to Fezf2-mediated SCPN subtype

224 refinement. To address this question, we designed an approach combining small

225 molecule screening with transient Fezf2 induction: 1) directed mES cell differentiation to 
Sadegh et al. 11

226 day 14 neocortical-like progenitors, 2) addition of a small molecule library and incubation

227 for four days to precondition the cells to a more permissive epigenetic landscape, 3) Fezf2

228 modRNA transfection and incubation for two days to direct SCPN subtype refinement,

229 and 4) immunohistochemical assessment using multiple exclusionary markers to

230 evaluate the extent of SCPN identity refinement (Figure S3A). We designed a custom

231 library of eighty small molecules modulating known epigenetic enzymes, with targets

232 including histone deacetylases, methyltransferases, and kinases (Figure S3B). Using

233 automated confocal imaging, cell segmentation, and threshold analyses, we quantified

234 the expression of both CTIP2 and SATB2 by individual neurons (Figure S3C,D).

We used multiple selection criteria to identify leading candidates. In the first assay,

236 we found that multiple Sirtuin modulators can either enhance or diminish Fezf2-mediated

237 subtype refinement, as indicated by our metric of SCPN identity refinement, which is the

238 ratio of maturing $\mathrm{CTIP}^{+} / \mathrm{SATB} 2^{-}$neurons to relatively immature CTIP2 ${ }^{+} / \mathrm{SATB}^{+}$double-

239 positive neurons (Figure 2A). Focusing on small molecules that might enhance Fezf2-

240 mediated refinement of $\mathrm{CTIP2}^{+} / \mathrm{SATB}^{-}$expression, we then asked which small

241 molecules globally increase the total number of CTIP2 expressing neurons, relative to

242 Fezf2 modRNA induction alone (Figure 2B). In a third level assay, we tested a smaller

243 group of leading candidate small molecules for their ability to either maintain or decrease

244 the total number of SATB2 expressing neurons compared with Fezf2 induction alone

245 (Figure 2C). Optimized by these stringent criteria and given the prevalence of candidates

246 independently targeting the same Sirtuin pathway, we chose the SIRT1 inhibitor EX-527

247 as a leading candidate to enhance Fezf2-mediated SCPN differentiation. As an internal

248 control, we compared the activity of EX-527 to other Sirtuin inhibitors and activators. Non- 
Sadegh et al. 12

249 specific Sirtuin inhibitors (nicotinamide, forskolin, and tenovin-6) do not increase SCPN

250 refinement. Reinforcing these results, the SIRT1-specific activator (CAY10591) displays

251 antagonism to SCPN refinement. modRNA, because Fezf2 is already highly expressed by primary SCPN progenitors.

257 Dissociated E12.5 neocortical neurons were treated with small molecule inhibitors of 258 SIRT1 for six days. We again identified EX-527, and an even more specific SIRT1 259 inhibitor, CHIC-35, as potent enhancers of CTIP2 ${ }^{+} /$SATB2$^{-}$subtype identity refinement 260 (Figure 3A). CHIC-35 is highly SIRT1-specific, with a binding site within the SIRT1 261 catalytic cleft that blocks substrate binding (Napper et al., 2005; Zhao et al., 2013). 262 Compared to non-specific inhibitors, both EX-527 and CHIC-35 show selective 263 enhancement of SCPN molecular refinement (Figure 3A). Notably, there was no 264 observable change in the density of cultured cells following small molecule application, 265 which was confirmed by automated cell segmentation analysis demonstrating stable cell 266 counts, sizes, and fluorescence in the imaging wells across conditions. 
Sadegh et al. 13

272 expression later becomes restricted to CPN and corticothalamic projection neurons, 273 becomes excluded from SCPN, and is overall restricted to primary sensory areas. We

274 find that the strategy of small molecule SIRT1 inhibition additionally promotes

275 CTIP2 $^{+} /$CTIP1- $^{-}$subtype distinction (Figure 3B). Based on both CTIP2 ${ }^{+} /$SATB2 $^{-}$and

$276 \mathrm{CTIP}^{+}{ }^{+}$CTIP1- subtype distinction in the context of Fezf2 expression, these data indicate

277 that SIRT1 inhibition enhances and enables Fezf2 refinement of neocortical subtype 278 identity toward SCPN.

Given the known roles of SIRT1 in cortical neural progenitor differentiation and neuronal survival (Prozorovski et al., 2008; Li et al., 2008; Tiberi et al., 2012; Hisahara et al., 2008; Herskovits and Guarente, 2014; Cai et al., 2016; Iwata et al., 2020) and post-

282 mitotic cortical neuron genomic stability (Dobbin et al. 2013), we next tested an alternative 283 theoretical hypothesis that SIRT1 inhibition might potentially alter the proportions of 284 progenitors and neurons, giving an impression of post-mitotic subtype distinction, while 285 instead acting at the progenitor level. To the contrary, we find that the increase in 286 proportion of CTIP2-expressing neurons is nearly completely compensated by the 287 reduction of $\mathrm{CTIP}^{+} / \mathrm{SATB}^{+}$dual expressing neurons (Figure $3 \mathrm{C}, \mathrm{D}$ ). Because the 288 combined fraction of CTIP2- and SATB2-expressing neurons remains constant between 289 samples, these experiments indicate that the subtype refinement phenotype is not due to 290 changes in the proliferation of neocortical progenitors.

Although EX-527 and CHIC-35 are highly specific small molecule inhibitors of 292 SIRT1 (Zhao et al., 2013), we pursued Sirt1-specific molecular knockdown with siRNA to 293 further confirm whether SIRT1 is the main target of repression in primary dissociated 294 neocortical neurons. We find that Sirt1 knockdown in primary dissociated E12.5 
Sadegh et al. 14

295 neocortical neurons recapitulates the effect of small molecule inhibition of SIRT1,

296 increasing both CTIP2 ${ }^{+} /$SATB2$^{-}$and CTIP2 ${ }^{+} / \mathrm{CTIP} 1^{-}$subtype-specific SCPN identity

297 refinements (Figure S4).

SIRT1 expression in vivo is CPN subtype-specific

We next investigated whether in vivo SIRT1 expression is consistent with the

301 results of the screening approach in mES-derived neurons. We used

302 immunocytochemistry to investigate SIRT1 protein localization in the developing mouse

303 neocortex. At P4, we find that SIRT1 is expressed throughout the rostro-caudal extent of

304 the neocortex, in layers II/III, V (at a relatively lower level), VI, and subplate (Figure 4A).

305 While SIRT1 expression is broadly distributed, as previously reported (Hasegawa and

306 Yoshikawa, 2008; Michan and Sinclair, 2007; Qin et al., 2006), we hypothesized that its

307 level of expression varies in distinct neocortical subtypes. Strikingly, we find that SIRT1

308 expression is subtype-specific by $\mathrm{E} 18.5$, with near complete co-localization with SATB2-

309 expressing CPN in layers II/III, V, and VI, and exclusion by CTIP2-expressing SCPN/CSN

310 in layer V (Figure 4B). Similarly, at P4, SIRT1 expression is excluded from increasingly

311 mature SCPN/CSN (Figure 4C).

We next asked whether SIRT1 is differentially transcribed in pure populations of 313 retrogradely-labeled CPN versus CSN, the important subtype of SCPN in layer $V$ that

314 project axons to the spinal cord. Using an existing microarray-based comparative gene 315 expression analysis of retrogradely-labeled CPN and CSN (Arlotta et al., 2005;

316 Molyneaux et al., 2009), we find that SIRT1 is the only differentially expressed histone 317 deacetylase (HDAC) throughout post-mitotic neocortical differentiation at E18.5, P3, P6, 
Sadegh et al. 15

318 and P14, with highest expression by CPN at all ages (Figure S5). Combined with the

319 protein expression data in Figure 4, these results demonstrate that Sirt1 mRNA and

320 protein are specifically and highly expressed by SATB2-expressing CPN subtypes during

321 corticogenesis, and are expressed at significantly lower levels by CTIP2-expressing

322 SCPN/CSN during early, middle, and late stages of subtype identity refinement. These in

323 vivo findings support the CPN-specific expression of SIRT1, and its relative exclusion

324 from SCPN/CSN and other neocortical neurons.

325 Together, these data describe a context-specific role for SIRT1 in fine-tuning

326 SCPN/CSN post-mitotic identity refinement during late embryonic neocortical

327 development. Identified by high content, small molecule screening of epigenetic factors,

328 SIRT1 inhibition enhances SCPN/CSN molecular refinement among primary dissociated

329 E12.5 neocortical neurons and complements the approach of using transient Fezf2

330 modRNA expression to promote SCPN/CSN identity refinement among heterogeneous

331 mES-derived neocortical-like neurons. 
Sadegh et al. 16

\section{2}

333

334

335

336

337

338

339

340

341

342

343

344

345

346

347

348

349

350

351

352

353

354

\section{Discussion}

Our data indicate that Sirt1 inhibition or knockdown approaches are effective for the refinement of ES-derived SCPN/CSN in vitro, and suggest that SIRT1 is functionally important for the refinement of SCPN/CSN identity in vivo during mouse neocortical development. This is likely also relevant for human iPSC directed differentiation into SCPN/CSN. From the initial screening experiment (Figure 2), we find that inhibition of SIRT1 preceding Fezf2 induction enhances SCPN/CSN identity refinement in mESderived neocortical neurons. Within primary mouse neocortical neurons, we identify that Sirt1 inhibition, by either small molecule or knockdown approaches, promotes mature molecular refinement of Fezf2-mediated SCPN/CSN identity (Figure 3, Figure S4). Although Sirt1-null mice have not yet been assessed for subtype-specific deficits in the neocortex, their gross neocortical anatomy (e.g. intact corpus callosum, absence of Probst bundles) appears intact (Cheng et al., 2003; McBurney et al., 2003; Michán et al., 2010), suggesting that Sirt1 is not required for CPN specification.

SIRT1 is a ubiquitously expressed NAD-dependent histone deacetylase (HDAC) with context-dependent roles in neocortical differentiation (Hisahara et al., 2008; Tiberi et al., 2012). At early developmental stages, SIRT1 regulates neurogenesis within neocortical progenitors by repressing the Notch-Hes pathway (Tiberi et al., 2012). Later in development, SIRT1 is ubiquitously expressed, with minimal enrichment in the upper layers of mouse neocortex at E14.5 and at 10 months of age, although the level of SIRT1 expression by specific neocortical subtypes had not been previously assessed (Hasegawa and Yoshikawa, 2008; Michan and Sinclair, 2007; Qin et al., 2006). We find that neocortical SCPN/CSN have markedly reduced SIRT1 expression in mid- to late- 
corticogenesis, in contrast to deep and superficial layer CPN that are relatively enriched for SIRT1 expression (Figure 4, Figure S5). Based on these results, SIRT1 should be considered to have neuronal subtype specificity as a chromatin modifier in the neocortex (Molyneaux et al., 2005; MacDonald and Roskams, 2008; Molyneaux et al., 2009). differentiation. First, transient Fezf2 expression is sufficient to generate SCPN/CSN in Fezf2-null mice at E12.5, but not at E15.5 (Figure 1). At later ages (E13.5 through P7), a higher dose or duration of Fezf2 expression (e.g., by plasmid vector) can re-specify alternate neocortical subtypes toward most aspects of SCPN/CSN identity (Molyneaux et al., 2005; Chen et al., 2008; Rouaux and Arlotta, 2013; De la Rossa et al., 2013). However, after E15.5, mis-expression of Fezf2 does not induce Ctip2 expression in most neurons, highlighting context specificity (Chen et al., 2008; Rouaux and Arlotta, 2013; De la Rossa et al., 2013). Together, these prior in vivo findings indicate that E12.5 is the optimal molecular context to most completely enable Fezf2-mediated specification of

370 SCPN, induction of Ctip2 expression, and stable epigenetic silencing of Satb2.

371 Consistently, in vitro, high dose Fezf2 induction (plasmid or viral mediated) by neocortical-

372 like neurons does not alone induce SCPN/CSN identity (Wang et al., 2011; Sadegh, 373 unpublished data, 2011). Moreover, when Fezf2 modRNA is induced within mES-derived

374 neocortical cells at a time approximating E12.5 neocortical differentiation, it alone does

375 not significantly increase SCPN/CSN subtype-specific transcription factor expression

376 (Figure S2). These in vitro data indicate that, although the timing of Fezf2 expression is

377 important, this cannot be accomplished by targeting cells with a suboptimal chromatin 
Sadegh et al. 18

378 landscape, as would be expected in maturation-stalled ES-derived neocortical neurons

379 (Sadegh and Macklis, 2014).

CPN are an evolutionarily more recent and diversified subtype of neocortical neurons, and likely employ multiple sequential epigenetic mechanisms in their specification, molecular refinement, and maturation (Molyneaux et al., 2009; MacDonald and Roskams, 2009; Kishi and Macklis, 2010; Fame et al., 2011; Fame et al., 2016a; Fame et al. 2016b). At late stages of maturation of layer 2/3 CPN (e.g. eight postnatal weeks in mice), the widely expressed methyl binding protein MeCP2 is required for proper development and/or maintenance of dendritic complexity and soma size (Kishi and Macklis, 2004, 2010; Kishi et al., 2016). At earlier stages of CPN development, SATB2 is required for proper differentiation, indirectly guiding chromatin remodeling by binding to matrix attachment regions (MAR) and recruiting HDAC enzymes through a binding partner, SKI (Britanova et al., 2005; Britanova et al., 2008; Alcamo et al., 2008; Gyorgy et al., 2008; Baranek et al., 2012). Together - with varying extents of CPN-specificity SIRT1, SATB2/SKI, MeCP2, and likely others might coordinate chromatin remodeling in CPN at distinct stages of development. remarkable because SIRT1 is implicated in the oxidative stress response and survival of

397 be resistant to metabolic insults, it raises the possibility that SCPN/CSN, by virtue of

398 having reduced SIRT1 expression, might be more sensitive to metabolic stress. SCPN 399 and especially the subpopulation of corticospinal neurons (CSN) are the brain neurons 400 that selectively degenerate in amyotrophic lateral sclerosis (ALS; Ozdinler and Macklis, 
Sadegh et al. 19

401 2006; Zang and Cheema, 2002). Intriguingly, Sirt1 over-expression has been shown to 402 promote short-term survival of dissociated neocortical neurons mis-expressing ALS 403 associated mutant SOD1 (Kim et al., 2007). More broadly, non-specific HDAC inhibitors 404 show neuroprotective properties in mouse models of ALS (Petri et al., 2006; Rouaux et 405 al., 2007).

406 Overall, our findings indicate subtype-specific functions for SIRT1 in the molecular 407 refinement of neocortical SCPN/CSN versus CPN identity. Importantly, these results 408 demonstrate the utility of combining epigenetic priming with subtype-specific transcription 409 factor induction in ES (and not unlikely, human iPSC) directed differentiation. These

410 results provide a proof-of-concept strategy for specific and progressive enhancement of 411 directed CSN/SCPN or other subtype differentiation from pluripotent cells. These results 412 further suggest that subtype-specific epigenetic modulation might enhance optimal in vitro 413 generation of other diverse neocortical neuron subtypes. 
Sadegh et al. 20

\section{Methods}

RNA synthesis and transfection

Synthetic modified RNA (modRNA) was generated as previously described

418 (Warren et al., 2010). Briefly, RNA was synthesized with the MEGAscript T7 kit (Ambion,

419 Austin, TX). A custom ribonucleoside blend was used, comprising 6 mM 5' cap analog

420 (New England Biolabs), $7.5 \mathrm{mM}$ adenosine triphosphate and $1.5 \mathrm{mM}$ guanosine 421 triphosphate (USB, Cleveland, $\mathrm{OH}$ ), $7.5 \mathrm{mM}$ 5-methylcytidine triphosphate and $7.5 \mathrm{mM}$

422 pseudo-uridine triphosphate (TriLink Biotechnologies, San Diego, CA). Transfections of

423 modRNA and multiple siRNA targeted against Sirt1 and Satb2 (both from Santa Cruz)

424 were carried out with RNAiMAX (Invitrogen), as per the manufacturer's instructions.

Cell culture and differentiation

Feeder-free E14Tg2a (Baygenomics) mouse embryonic stem cells (mES) were passaged on gelatin-coated $(0.1 \%$ gelatin, StemCell Technologies) cell culture treated

429 plastic dishes using established media and cell culture techniques (Sadegh and Macklis, 430 2014). For differentiation, mES were plated at low density $\left(5,000 \mathrm{cells} / \mathrm{cm}^{2}\right)$ on gelatin431 coated plastic dishes in ESC medium, and cultured as described (Gaspard et al., 2009). Cyclopamine (Calbiochem) was added from day 2 to day 10 in the differentiation 433 medium at a final concentration of $1 \mathrm{uM}$. After 10 to 14 days of differentiation, cells were 434 trypsinized, dissociated, and plated on poly-lysine/laminin (Becton-Dickinson) coated 435 glass coverslips, and allowed to grow for 4-14 days in N2B27 medium (Gaspard et al., 436 2009). 
Sadegh et al. 21

A high content screening protocol was adapted from Makhortova et al. (2011).

440 Briefly, mES were seeded at 5,000 cells per well in 96-well plates, and treated in duplicate

441 at $10 \mu \mathrm{M}, 1 \mu \mathrm{M}$, and $0.1 \mu \mathrm{M}$ with individual compounds from the screening library, a

442 custom set of 80 chemicals affecting histone deacetylases, methyltransferases, and

443 kinases. Most small molecules, including EX-527 (Sigma), CHIC-35 (Sigma), and

444 nicotinamide (Sigma), were re-suspended in DMSO, according to the manufacturer's 445 instructions.

447 Opera) at 20X magnification with separate fluorescence exposures from a UV light source 448 and 488, 546, and 647nm lasers. Image analysis was performed using Columbus 449 software (version 2.3.0; PerkinElmer; see also Figure S3C,D), which automatically set 450 the boundaries of cell nuclei based on Hoechst staining. These boundaries were 451 optimized by manual inspection to exclude nuclear fragments or adjacent double nuclei 452 based on the total area and staining intensity of Hoechst-positive nuclei. Next, the 453 intensity of antibody labeling for each distinct transcription factor in each nucleus was 454 quantified. The threshold for positive antibody labeling was manually established 455 individually for CTIP2, SATB2, and CTIP1, compared to baseline labeling without primary 456 antibody (omission of primary controls). This threshold for labeling a nucleus positive for 457 individual transcription factor expression was calibrated to approximately $20 \%$ of the 458 maximum average pixel intensity observed in other nuclei for that transcription factor. 459 Setting this threshold for positive labeling was necessary because populations of mES- 
460 derived neurons express a near-continuum of transcription factor labeling intensities, 461 creating a large population of cells with simultaneous faint nuclear expression of multiple

462 transcription factors, which could be interpreted as indicative of atypical transcriptional 463 regulation ("confused" neurons). This is in striking contrast with the expression levels 464 exhibited by bona fide populations of primary dissociated E15.5 mouse neocortical 465 neurons, using the same labeling and analysis methods. These primary neurons typically 466 display much more distinctly grouped average pixel intensities for each nucleus, with 467 largely trimodal labeling that can be quantitatively delineated (negative, low expression, 468 high expression).

472 type CD1 mice were used in all other experiments (Charles River Laboratories). The date

473 of vaginal plug detection was designated E0.5, and the day of birth as P0. Mice used in

474 these experiments were handled according to guidelines of the National Institutes of 475 Health $(\mathrm{NIH})$, and all procedures were conducted in accordance with Harvard University's 476 institutional guidelines. 
482 Abcam); rabbit antibody to SIRT1 (1:250, Millipore); rabbit antibody to CTIP1 (1:500, 483 Abcam); rabbit antibody to GFP (1:500, Invitrogen); chicken antibody to NESTIN (1:500, 484 Novus Biologicals); mouse antibody to TuJ1 (1:500, Covance); mouse antibody to MAP2 485 (1:500, Sigma); and mouse antibody to NeuN (1:250, Millipore). Alexa fluorophore 486 conjugated secondary antibodies from Invitrogen were used at a dilution of 1:1000. 487 Hoechst 33342 counterstain was used to visualize nuclei (1:3,000, Invitrogen). 
488 Author contributions: C.S. and J.D.M. designed research; C.S. performed research; 489 C.S. and J.D.M. analyzed data; C.S. and J.D.M. wrote the manuscript. W.E. provided

490 expertise for the application of synthetic modified mRNA technology, reagent support,

491 and discussion for this work. T.A., L.D., and L.L.R. provided expertise for small

492 molecule screening, reagent support, and discussions.

493

\section{Acknowledgments}

We thank Dr. Derrick J. Rossi for his laboratory's technical and reagent support for 496 modRNA generation, testing, and optimization. We thank A. Gee, Dr. K. Haston, and C.

497 Goldstein (L. Rubin laboratory) for sharing their expertise in cell culture and high content 498 screening, sharing of reagents, and technical assistance. We also thank Drs. T. Wuttke 499 and H. Padmanabhan (J.D.M. laboratory) for help with primary neuron isolation, and 500 expert advice, respectively.

502 grant for the ES/iPS Directed Neuronal Subtype Differentiation collaborative program of 503 the HSCI Nervous System Diseases Program, and by the Max and Anne Wien Professor 504 of Life Sciences fund. This study was also supported by NIH grants NS45523 and 505 NS41590, with additional infrastructure supported by NS49553 and NS75672, and with 506 additional support from the Jane and Lee Seidman Fund for Central Nervous System 507 Research, and the Emily and Robert Pearlstein Fund for Nervous System Repair (J.D.M.). 508 C.S. was partially supported by T32 GM007753-30 (NIH Medical Scientist Training 509 Program) and T32 AG000222-18 (Harvard Medical School, Division of Medical 510 Sciences). 
Sadegh et al. 25

\section{References}

Alcamo, E., Chirivella, L., Dautzenberg, M., Dobreva, G., Fariñas, I., Grosschedl, R. and McConnell, S. (2008). "Satb2 regulates callosal projection neuron identity in the developing cerebral cortex." Neuron 57(3): 364-377.

Angel, M. and Yanik, M. (2010). "Innate immune suppression enables frequent transfection with RNA encoding reprogramming proteins." PLoS One 5(7): e11756.

Arlotta, P., Molyneaux, B., Chen, J., Inoue, J., Kominami, R. and Macklis, J. (2005). "Neuronal Subtype-Specific Genes that Control Corticospinal Motor Neuron Development In Vivo." Neuron 45(2): 207-221.

Arlotta, P. (2018) "Organoids required! A new path to understanding human brain development and disease." Nat Methods. 15(1):27-29.

Azim, E. (2009, Dissertation). "Molecular Controls over Neocortical Neuronal Diversity and Oligodendrocyte Development." Harvard University Ph.D. Dissertation.

Azim, E., Shnider, S., Cederquist, G., Sohur, U. and Macklis, J. (2009). "Lmo4 and Clim1 Progressively Delineate Cortical Projection Neuron Subtypes during Development." Cereb Cortex 19(Suppl 1): i62-i69.

Baranek, C., Dittrich, M., Parthasarathy, S., Bonnon, C., Britanova, O., Lanshakov, D., Boukhtouche, F., Sommer, J., Colmenares, C., Tarabykin, V. and Atanasoski, S. (2012). "Protooncogene Ski cooperates with the chromatin-remodeling factor Satb2 in specifying callosal neurons." Proc Natl Acad Sci USA 109(9): 3546-3551.

Briggs, J.A., Li, V.C., Lee, S., Woolf, C.J., Klein, A., Kirschner, M.W. (2017) "Mouse embryonic stem cells can differentiate via multiple paths to the same state." eLife 6:e26945.

Britanova, O., Akopov, S., Lukyanov, S., Gruss, P. and Tarabykin, V. (2005). "Novel transcription factor Satb2 interacts with matrix attachment region DNA elements in a tissue-specific manner and demonstrates cell-type-dependent expression in the developing mouse CNS." Eur J Neurosci 21(3): 658-668.

Britanova, O., De Juan Romero, C., Cheung, A., Kwan, K., Schwark, M., Gyorgy, A., Vogel, T., Akopov, S., Mitkovski, M., Agoston, D., Šestan, N., Molnár, Z. and Tarabykin, V. (2008). "Satb2 Is a Postmitotic Determinant for Upper-Layer Neuron Specification in the Neocortex." Neuron 57(3): 378-392.

Cai, S., Han, H.-J. and Kohwi-Shigematsu, T. (2003). "Tissue-specific nuclear architecture and gene expression regulated by SATB1." Nature genetics 34(1): 42-51.

Cai, Y., Xu, L., Xu, H., Fan, X. (2016) "SIRT1 and Neural Cell Fate Determination" 
Sadegh et al. 26

Mol Neurobiol. 53(5):2815-2825.

Cederquist, G., Azim, E., Shnider, S., Padmanabhan, H. and Macklis, J. (2013). "Lmo4 establishes rostral motor cortex projection neuron subtype diversity." J Neurosci 33(15): 6321-6332.

Chen, B., Schaevitz, L. R. and McConnell, S. K. (2005). "Fezl regulates the differentiation and axon targeting of layer 5 subcortical projection neurons in cerebral cortex." Proc Natl Acad Sci USA 102(47): 17184-17189.

Chen, B., Wang, S. S., Hattox, A. M., Rayburn, H., Nelson, S. B. and McConnell, S. K. (2008). "The Fezf2-Ctip2 genetic pathway regulates the fate choice of subcortical projection neurons in the developing cerebral cortex." Proc Natl Acad Sci USA 105(32): 11382-11387.

Cheng, H.-L., Mostoslavsky, R., Saito, S. i., Manis, J., Gu, Y., Patel, P., Bronson, R., Appella, E., Alt, F. and Chua, K. (2003). "Developmental defects and p53 hyperacetylation in Sir2 homolog (SIRT1)-deficient mice." Proc Natl Acad Sci USA 100(19): 10794-10799.

Chetty, S., Pagliuca, F., Honore, C., Kweudjeu, A., Rezania, A. and Melton, D. (2013). "A simple tool to improve pluripotent stem cell differentiation." Nature methods 10(6): 553556.

Cismasiu, V., Adamo, K., Gecewicz, J., Duque, J., Lin, Q. and Avram, D. (2005). "BCL11B functionally associates with the NuRD complex in $T$ lymphocytes to repress targeted promoter." Oncogene 24(45): 6753-6764.

De la Rossa, A., Bellone, C., Golding, B., Vitali, I., Moss, J., Toni, N., Lüscher, C. and Jabaudon, D. (2013). "In vivo reprogramming of circuit connectivity in postmitotic neocortical neurons." Nature neuroscience 16(2): 193-200.

Dobbin, M.M., Madabhushi, R., Pan, L., Chen, Y., Kim, D., Gao, J., Ahanonu, B., Pao, P.C., Qiu, Y., Zhao, Y., Tsai, L.H. (2013). " SIRT1 collaborates with ATM and HDAC1 to maintain genomic stability in neurons" Nature neuroscience 16(8):1008-15.

Dobreva, G., Dambacher, J. and Grosschedl, R. (2003). "SUMO modification of a novel MAR-binding protein, SATB2, modulates immunoglobulin mu gene expression." Genes Dev 17(24): 3048-3061.

Eiraku, M., Watanabe, K., Matsuo-Takasaki, M., Kawada, M., Yonemura, S., Matsumura, M., Wataya, T., Nishiyama, A., Muguruma, K. and Sasai, Y. (2008). "Self-organized formation of polarized cortical tissues from ESCs and its active manipulation by extrinsic signals." Cell Stem Cell 3(5): 519-532.

Fame, R., MacDonald, J. and Macklis, J. (2011). "Development, specification, and diversity of callosal projection neurons." Trends in neurosciences 34(1): 41-50. 
Sadegh et al. 27

602

603

604

605

606

607

608

609

610

611

612

613

614

615

616

617

618

619

620

621

622

623

624

625

626

627

628

629

630

631

632

633

634

635

636

637

638

639

640

641

642

643

644

645

646

647

Fame, R. M., Dehay, C., Kennedy, H., Macklis, J. D. (2017). "Subtype-Specific Genes that Characterize Subpopulations of Callosal Projection Neurons in Mouse Identify Molecularly Homologous Populations in Macaque Cortex." Cereb Cortex 1;27(3):18171830

Fame, R. M., MacDonald, J. L., Dunwoodie, S. L., Takahashi, E., Macklis, J. D. (2016). "Cited2 Regulates Neocortical Layer II/III Generation and Somatosensory Callosal Projection Neuron Development and Connectivity." J Neurosci 36(24): 6403-19.

Galazo, M. J., Emsley, J. G., and Macklis J. D. (2016). "Corticothalamic Projection Neuron Development beyond Subtype Specification: Fog2 and Intersectional Controls Regulate Intraclass Neuronal Diversity." Neuron 91: 90-106.

Gaspard, N., Bouschet, T., Herpoel, A., Naeije, G., van den Ameele, J. and Vanderhaeghen, P. (2009). "Generation of cortical neurons from mouse embryonic stem cells." Nat Protoc 4(10): 1454-1463.

Gaspard, N., Bouschet, T., Hourez, R., Dimidschstein, J., Naeije, G., Van Den Ameele, J., Espuny-Camacho, I., Herpoel, A., Passante, L., Schiffmann, S., Gaillard, A. and Vanderhaeghen, P. (2008). "An intrinsic mechanism of corticogenesis from embryonic stem cells." Nature 455(7211): 351-357.

Gräff, J. and Tsai, L.-H. (2013). "Histone acetylation: molecular mnemonics on the chromatin." Nature reviews. Neuroscience 14(2): 97-111.

Greig, L. C., Woodworth, M. B., Greppi, C., Macklis, J. D. (2016). "Ctip1 Controls Acquisition of Sensory Area Identity and Establishment of Sensory Input Fields in the Developing Neocortex." Neuron 90(2): 261-77.

Greig, L. C., Woodworth, M. B., Galazo, M. J., Padmanabhan, H. and Macklis, J. D. (2013). "Molecular logic of neocortical projection neuron specification, development and diversity." Nature Reviews Neuroscience 14.

Gyorgy, A., Szemes, M., de Juan Romero, C., Tarabykin, V. and Agoston, D. (2008). "SATB2 interacts with chromatin-remodeling molecules in differentiating cortical neurons." Eur J Neurosci 27(4): 865-873.

Haigis, M. C. and Sinclair, D. A. (2010). "Mammalian Sirtuins: Biological Insights and Disease Relevance." Annual Review of Pathology: Mechanisms of Disease 5: 253-295.

Hasegawa, K. and Yoshikawa, K. (2008). "Necdin regulates p53 acetylation via Sirtuin1 to modulate DNA damage response in cortical neurons." J Neurosci 28(35): 8772-8784.

Herskovits, A.Z., Guarente, L. (2014) "SIRT1 in neurodevelopment and brain senescence." Neuron. 5;81(3):471-83 
Sadegh et al. 28

648

649

650

651

652

653

654

655

656

657

658

659

660

661

662

663

664

665

666

667

668

669

670

671

672

673

674

675

676

677

678

679

680

681

682

683

684

685

686

687

688

689

690

691

Hisahara, S., Chiba, S., Matsumoto, H., Tanno, M., Yagi, H., Shimohama, S., Sato, M. and Horio, Y. (2008). "Histone deacetylase SIRT1 modulates neuronal differentiation by its nuclear translocation." Proc Natl Acad Sci USA 105(40): 15599-15604.

Iwata, R., Vanderhaeghen, P. (2020). "Mitochondria dynamics in postmitotic cells drives neurogenesis through Sirtuin-dependent chromatin remodeling. bioRxiv doi: https://doi.org/10.1101/2020.02.07.938985

Joshi, P. S., Molyneaux, B. J., Feng, L., Xie, X., Macklis, J. D. and Gan, L. (2008). "Bhlhb5 regulates the postmitotic acquisition of area identities in layers II-V of the developing neocortex." Neuron 60(2): 258-272.

Juliandi, B., Abematsu, M., Sanosaka, T., Tsujimura, K., Smith, A. and Nakashima, K. (2012). "Induction of superficial cortical layer neurons from mouse embryonic stem cells by valproic acid." Neuroscience research 72(1): 23-31.

Kim, D., Nguyen, M., Dobbin, M., Fischer, A., Sananbenesi, F., Rodgers, J., Delalle, I., Baur, J., Sui, G., Armour, S., Puigserver, P., Sinclair, D. and Tsai, L.-H. (2007). "SIRT1 deacetylase protects against neurodegeneration in models for Alzheimer's disease and amyotrophic lateral sclerosis." EMBO J 26(13): 3169-3179.

Kishi, N. and Macklis, J. D. (2004). "MECP2 is progressively expressed in post-migratory neurons and is involved in neuronal maturation rather than cell fate decisions." Mol Cell Neurosci 27(3): 306-321.

Kishi, N. and Macklis, J. D. (2010). "MeCP2 functions largely cell-autonomously, but also non-cell-autonomously, in neuronal maturation and dendritic arborization of cortical pyramidal neurons." Exp Neurol 222: 51-58.

Kishi, Y., Fujii, Y., Hirabayashi, Y. and Gotoh, Y. (2012). "HMGA regulates the global chromatin state and neurogenic potential in neocortical precursor cells." Nature neuroscience 15(8): 1127-1133.

Kishi, N., MacDonald, J. L., Ye, J., Molyneaux, B. J., Azim, E., Macklis, J. D. (2016). "Reduction of aberrant NF-KB signalling ameliorates Rett syndrome phenotypes in Mecp2-null mice." Nat Commun 7:10520.

Kormann, M., Hasenpusch, G., Aneja, M., Nica, G., Flemmer, A., Herber-Jonat, S., Huppmann, M., Mays, L., Illenyi, M., Schams, A., Griese, M., Bittmann, I., Handgretinger, R., Hartl, D., Rosenecker, J. and Rudolph, C. (2011). "Expression of therapeutic proteins after delivery of chemically modified mRNA in mice." Nature biotechnology 29(2): 154157. 
Sadegh et al. 29

692

693

694

695

696

697

698

699

700

701

702

703

704

705

706

707

708

709

710

711

712

713

714

715

716

717

718

719

720

721

722

723

724

725

726

727

728

729

730

731

732

733

734

735

736

737

Lai, T., Jabaudon, D., Molyneaux, B. J., Azim, E., Arlotta, P., Menezes, J. R. and Macklis, J. D. (2008). "SOX5 controls the sequential generation of distinct corticofugal neuron subtypes." Neuron 57(2): 232-247.

Lancaster, M.A., Renner, M., Martin, C.A., Wenzel, D., Bicknell, L.S., Hurles, M.E., Homfray, T., Penninger, J.M., Jackson, A.P., Knoblich, J.A. (2013) "Cerebral organoids model human brain

development and microcephaly." Nature. 501(7467):373-9.

Leid, M., Ishmael, J., Avram, D., Shepherd, D., Fraulob, V. and Dollé, P. (2004). "CTIP1 and CTIP2 are differentially expressed during mouse embryogenesis." Gene expression patterns : GEP 4(6): 733-739.

Leone, D.P., Heavner, W.E., Ferenczi, E.A., Dobreva, G., Huguenard, J.R., Grosschedl, R., McConnell, S.K. (2015) "Satb2 Regulates the Differentiation of Both Callosal and Subcerebral Projection Neurons in the Developing Cerebral Cortex." Cereb Cortex. 25(10):3406-19.

Li, Y., Xu, W., McBurney, M. and Longo, V. (2008). "SirT1 inhibition reduces IGF-I/IRS2/Ras/ERK1/2 signaling and protects neurons." Cell metabolism 8(1): 38-48.

MacDonald, J. and Roskams, A. (2008). "Histone deacetylases 1 and 2 are expressed at distinct stages of neuro-glial development." Developmental dynamics 237(8): 2256-2267.

MacDonald, J. and Roskams, A. (2009). "Epigenetic regulation of nervous system development by DNA methylation and histone deacetylation." Progress in neurobiology 88(3): 170-183.

Makhortova, N., Hayhurst, M., Cerqueira, A., Sinor-Anderson, A., Zhao, W., Heiser, P., Arvanites, A., Davidow, L., Waldon, Z., Steen, J., Lam, K., Ngo, H. and Rubin, L. (2011). "A screen for regulators of survival of motor neuron protein levels." Nat Chem Biol 7(8): 544-552.

Mandal, P.K., Rossi D.J. (2013). "Reprogramming human fibroblasts to pluripotency using modified mRNA." Nat Protoc. Mar;8(3):568-82.

Mariani, J., Simonini, M., Palejev, D., Tomasini, L., Coppola, G., Szekely, A., Horvath, T. and Vaccarino, F. (2012). "Modeling human cortical development in vitro using induced pluripotent stem cells." Proc Natl Acad Sci USA 109(31): 12770-12775.

Mays, L. E., Ammon-Treiber, S., Mothes, B., Alkhaled, M., Rottenberger, J., MüllerHermelink, E. S., Grimm, M., Mezger, M., Beer-Hammer, S., Stebut, E. v., Rieber, N., Nürnberg, B., Schwab, M., Handgretinger, R., Idzko, M., Hartl, D. and Kormann, M. S. D. (2013). "Modified Foxp3 mRNA protects against asthma through an IL-10-dependent mechanism." Journal of Clinical Investigation 123(3): 1216-1228. 
Sadegh et al. 30

738

739

740

741

742

743

744

745

746

747

748

749

750

751

752

753

754

755

756

757

758

759

760

761

762

763

764

765

766

767

768

769

770

771

772

773

774

775

776

777

778

779

780

781

782
McBurney, M. W., Yang, X., Jardine, K., Hixon, M., Boekelheide, K., Webb, J. R., Lansdorp, P. M. and Lemieux, M. (2003). "The Mammalian SIR2 Protein Has a Role in Embryogenesis and Gametogenesis." Molecular and Cellular Biology 23(1): 38-54.

Michán, S., Li, Y., Chou, M., Parrella, E., Ge, H., Long, J., Allard, J., Lewis, K., Miller, M., Xu, W., Mervis, R., Chen, J., Guerin, K., Smith, L., McBurney, M., Sinclair, D., Baudry, M., de Cabo, R. and Longo, V. (2010). "SIRT1 is essential for normal cognitive function and synaptic plasticity." J Neurosci 30(29): 9695-9707.

Michan, S. and Sinclair, D. (2007). "Sirtuins in mammals: insights into their biological function." The Biochemical journal 404(1): 1-13.

Michelsen, K. A., Acosta-Verdugo, S., Benoit-Marand, M., Espuny-Camacho, I., Gaspard, N., Saha, B., Gaillard, A., Vanderhaeghen, P. (2015). "Area-specific reestablishment of damaged circuits in the adult cerebral cortex by cortical neurons derived from mouse embryonic stem cells." Neuron. 85(5): 982-997.

Miskinyte, G., Grønning Hansen, M., Monni, E., Lam, M., Bengzon, J., Lindvall, O., Ahlenius, H., Kokaia, Z. (2018). " Transcription factor programming of human ES cells generates functional neurons expressing both upper and deep layer cortical markers." PLoS ONE 13(10): e0204688.

Miyoshi, G. and Fishell, G. (2012). "Dynamic FoxG1 expression coordinates the integration of multipolar pyramidal neuron precursors into the cortical plate." Neuron 74(6): 1045-1058.

Molyneaux, B. J., Arlotta, P., Fame, R. M., MacDonald, J. L., MacQuarrie, K. L. and Macklis, J. D. (2009). "Novel subtype-specific genes identify distinct subpopulations of callosal projection neurons." J Neurosci 29(39): 12343-12354.

Molyneaux, B. J., Arlotta, P., Hirata, T., Hibi, M. and Macklis, J. D. (2005). "Fezl is required for the birth and specification of corticospinal motor neurons." Neuron 47(6): 817-831.

Molyneaux, B. J., Arlotta, P., Menezes, J. R. and Macklis, J. D. (2007). "Neuronal subtype specification in the cerebral cortex." Nat Rev Neurosci 8(6): 427-437.

Napper, A., Hixon, J., McDonagh, T., Keavey, K., Pons, J.-F., Barker, J., Yau, W., Amouzegh, P., Flegg, A., Hamelin, E., Thomas, R., Kates, M., Jones, S., Navia, M., Saunders, J., DiStefano, P. and Curtis, R. (2005). "Discovery of indoles as potent and selective inhibitors of the deacetylase SIRT1." Journal of medicinal chemistry 48(25): 8045-8054.

Ozdinler, P. H. and Macklis, J. D. (2006). "IGF-I specifically enhances axon outgrowth of corticospinal motor neurons." Nat Neurosci 9(11): 1371-1381. 
Sadegh et al. 31

783

784

785

786

787

788

789

790

791

792

793

794

795

796

797

798

799

800

801

802

803

804

805

806

807

808

809

810

811

812

813

814

815

816

817

818

819

820

821

822

823

824

825

826

827

Papp, B. and Plath, K. (2013). "Epigenetics of reprogramming to induced pluripotency." Cell 152(6): 1324-1343.

Pasca SP. (2018). "The rise of three-dimensional human brain cultures." Nature 24;553(7689):437-445

Petri, S., Kiaei, M., Kipiani, K., Chen, J., Calingasan, N. Y., Crow, J. P. and Beal, M. F. (2006). "Additive neuroprotective effects of a histone deacetylase inhibitor and a catalytic antioxidant in a transgenic mouse model of amyotrophic lateral sclerosis." Neurobiology of Disease 22(1): 40-49.

Petsch, B., Schnee, M., Vogel, A., Lange, E., Hoffmann, B., Voss, D., Schlake, T., Thess, A., Kallen, K.-J., Stitz, L. and Kramps, T. (2012). "Protective efficacy of in vitro synthesized, specific mRNA vaccines against influenza A virus infection." Nature biotechnology 30(12): 1210-1216.

Prozorovski, T., Schulze-Topphoff, U., Glumm, R., Baumgart, J., Schröter, F., Ninnemann, O., Siegert, E., Bendix, I., Brüstle, O., Nitsch, R., Zipp, F. and Aktas, O. (2008). "Sirt1 contributes critically to the redox-dependent fate of neural progenitors." Nature cell biology 10(4): 385-394.

Qin, W., Yang, T., Ho, L., Zhao, Z., Wang, J., Chen, L., Zhao, W., Thiyagarajan, M., MacGrogan, D., Rodgers, J., Puigserver, P., Sadoshima, J., Deng, H., Pedrini, S., Gandy, S., Sauve, A. and Pasinetti, G. (2006). "Neuronal SIRT1 activation as a novel mechanism underlying the prevention of Alzheimer disease amyloid neuropathology by calorie restriction." The Journal of biological chemistry 281(31): 21745-21754.

Rouaux, C. and Arlotta, P. (2010). "Fezf2 directs the differentiation of corticofugal neurons from striatal progenitors in vivo." Nat Neurosci 13(11): 1345-1347.

Rouaux, C. and Arlotta, P. (2013). "Direct lineage reprogramming of post-mitotic callosal neurons into corticofugal neurons in vivo." Nature cell biology 15(2): 214-221.

Rouaux, C., Panteleeva, I., René, F., Gonzalez de Aguilar, J.-L., Echaniz-Laguna, A., Dupuis, L., Menger, Y., Boutillier, A.-L. and Loeffler, J.-P. (2007). "Sodium valproate exerts neuroprotective effects in vivo through CREB-binding protein-dependent mechanisms but does not improve survival in an amyotrophic lateral sclerosis mouse model." J Neurosci 27(21): 5535-5545.

Sadegh, C., Macklis, J.D. (2014). "Established monolayer differentiation of mouse embryonic stem cells generates heterogeneous neocortical-like neurons stalled at a stage equivalent to midcorticogenesis." J Comp Neurol. 15;522(12): 2691-706

Sances, S., Bruijn, L.I., Chandran, S., Eggan, K., Ho, R., Klim, J.R., Livesey, M.R., Lowry, E., Macklis, J.D., Rushton, D., Sadegh, C., Sareen, D., Wichterle, H., Zhang, S-C., 
Sadegh et al. 32

828

829

830

831

832

833

834

835

836

837

838

839

840

841

842

843

844

845

846

847

848

849

850

851

852

853

854

855

856

857

858

859

860

861

862

863

864

865

866

867

868

869

870

871

872

873
Svendsen, C.N. (2016) "Modeling ALS with motor neurons derived from human induced pluripotent stem cells." Nat Neurosci. 19(4): 542-553.

Scandura, J., Roboz, G., Moh, M., Morawa, E., Brenet, F., Bose, J., Villegas, L., Gergis, U., Mayer, S., Ippoliti, C., Curcio, T., Ritchie, E. and Feldman, E. (2011). "Phase 1 study of epigenetic priming with decitabine prior to standard induction chemotherapy for patients with AML." Blood 118(6): 1472-1480.

Senawong, T., Peterson, V., Avram, D., Shepherd, D., Frye, R., Minucci, S. and Leid, M. (2003). "Involvement of the histone deacetylase SIRT1 in chicken ovalbumin upstream promoter transcription factor (COUP-TF)-interacting protein 2-mediated transcriptional repression." The Journal of biological chemistry 278(44): 43041-43050.

Senawong, T., Peterson, V. and Leid, M. (2005). "BCL11A-dependent recruitment of SIRT1 to a promoter template in mammalian cells results in histone deacetylation and transcriptional repression." Archives of biochemistry and biophysics 434(2): 316-325.

Shi, Y., Kirwan, P., Smith, J., Robinson, H. and Livesey, F. (2012). "Human cerebral cortex development from pluripotent stem cells to functional excitatory synapses." Nature neuroscience 15(3): 477-486.

Shim, S., Kwan, K., Li, M., Lefebvre, V. and Šestan, N. (2012). "Cis-regulatory control of corticospinal system development and evolution." Nature 486(7401): 74-79.

Tiberi, L., van den Ameele, J., Dimidschstein, J., Piccirilli, J., Gall, D., Herpoel, A. I., Bilheu, A. I., Bonnefont, J., lacovino, M., Kyba, M., Bouschet, T. and Vanderhaeghen, P. (2012). "BCL6 controls neurogenesis through Sirt1-dependent epigenetic repression of selective Notch targets." Nature neuroscience 15(12): 1627-1635.

Tomassy, G., De Leonibus, E., Jabaudon, D., Lodato, S., Alfano, C., Mele, A., Macklis, J. and Studer, M. (2010). "Area-specific temporal control of corticospinal motor neuron differentiation by COUP-TFI." Proc Natl Acad Sci USA 107(8): 3576-3581.

Topark-Ngarm, A., Golonzhka, O., Peterson, V., Barrett, B., Martinez, B., Crofoot, K., Filtz, T. and Leid, M. (2006). "CTIP2 associates with the NuRD complex on the promoter of p57KIP2, a newly identified CTIP2 target gene." The Journal of biological chemistry 281(43): 32272-32283.

Wang, Z., Boisvert, E., Zhang, X., Guo, M., Fashoyin, A., Du, Z., Zhang, S. and Li, X. (2011). "Fezf2 Regulates Telencephalic Precursor Differentiation from Mouse Embryonic Stem Cells." Cereb Cortex 21(9): 2177-2186.

Warren, L., Manos, P., Ahfeldt, T., Loh, Y.-H., Li, H., Lau, F., Ebina, W., Mandal, P., Smith, Z., Meissner, A., Daley, G., Brack, A., Collins, J., Cowan, C., Schlaeger, T. and Rossi, D. (2010). "Highly efficient reprogramming to pluripotency and directed differentiation of human cells with synthetic modified mRNA." Cell Stem Cell 7(5): 618-630. 
Sadegh et al. 33

874

875

876

877

878

879

880

881

882

883

884

885

886

887

888

889

890

891

892

893

894

895

896

897

898

899

900

901

902

903
Woodworth, M., Custo Greig, L., Kriegstein, A. and Macklis, J. (2012). "SnapShot: cortical development." Cell 151(4): 918-9180.

Woodworth, M. B., Greig, L. C., Liu, K. X., Ippolito, G. C., Tucker, H. O., Macklis, J. D. (2016). "Ctip1 Regulates the Balance between Specification of Distinct Projection Neuron Subtypes in Deep Cortical Layers." Cell Rep 15(5): 999-1012.

Yasui, D., Miyano, M., Cai, S., Varga-Weisz, P. and Kohwi-Shigematsu, T. (2002). "SATB1 targets chromatin remodelling to regulate genes over long distances." Nature 419(6907): 641-645.

Ying, Q. L., Stavridis, M., Griffiths, D., Li, M. and Smith, A. (2003). "Conversion of embryonic stem cells into neuroectodermal precursors in adherent monoculture." Nat Biotechnol 21(2): 183-186.

Yip, D., Corcoran, C., Alvarez-Saavedra, M., DeMaria, A., Rennick, S., Mears, A., Rudnicki, M., Messier, C. and Picketts, D. (2012). "Snf2l regulates Foxg1-dependent progenitor cell expansion in the developing brain." Developmental cell 22(4): 871-878.

Zang, D. and Cheema, S. (2002). "Degeneration of corticospinal and bulbospinal systems in the superoxide dismutase $1(\mathrm{G} 93 \mathrm{~A} \mathrm{G} 1 \mathrm{H})$ transgenic mouse model of familial amyotrophic lateral sclerosis." Neuroscience letters 332(2): 99-102.

Zhao, X., Allison, D., Condon, B., Zhang, F., Gheyi, T., Zhang, A., Ashok, S., Russell, M., MacEwan, I., Qian, Y., Jamison, J. and Luz, J. (2013). "The $2.5 \AA$ crystal structure of the SIRT1 catalytic domain bound to nicotinamide adenine dinucleotide (NAD+) and an indole (EX527 analogue) reveals a novel mechanism of histone deacetylase inhibition." Journal of medicinal chemistry 56(3): 963-969. 
bioRxiv preprint doi: https://doi.org/10.1101/2020.08.13.242230; this version posted August 13, 2020. The copyright holder for this preprint (which was not certified by peer review) is the author/funder, who has granted bioRxiv a license to display the preprint in perpetuity. It is made available under aCC-BY-NC-ND 4.0 International license.

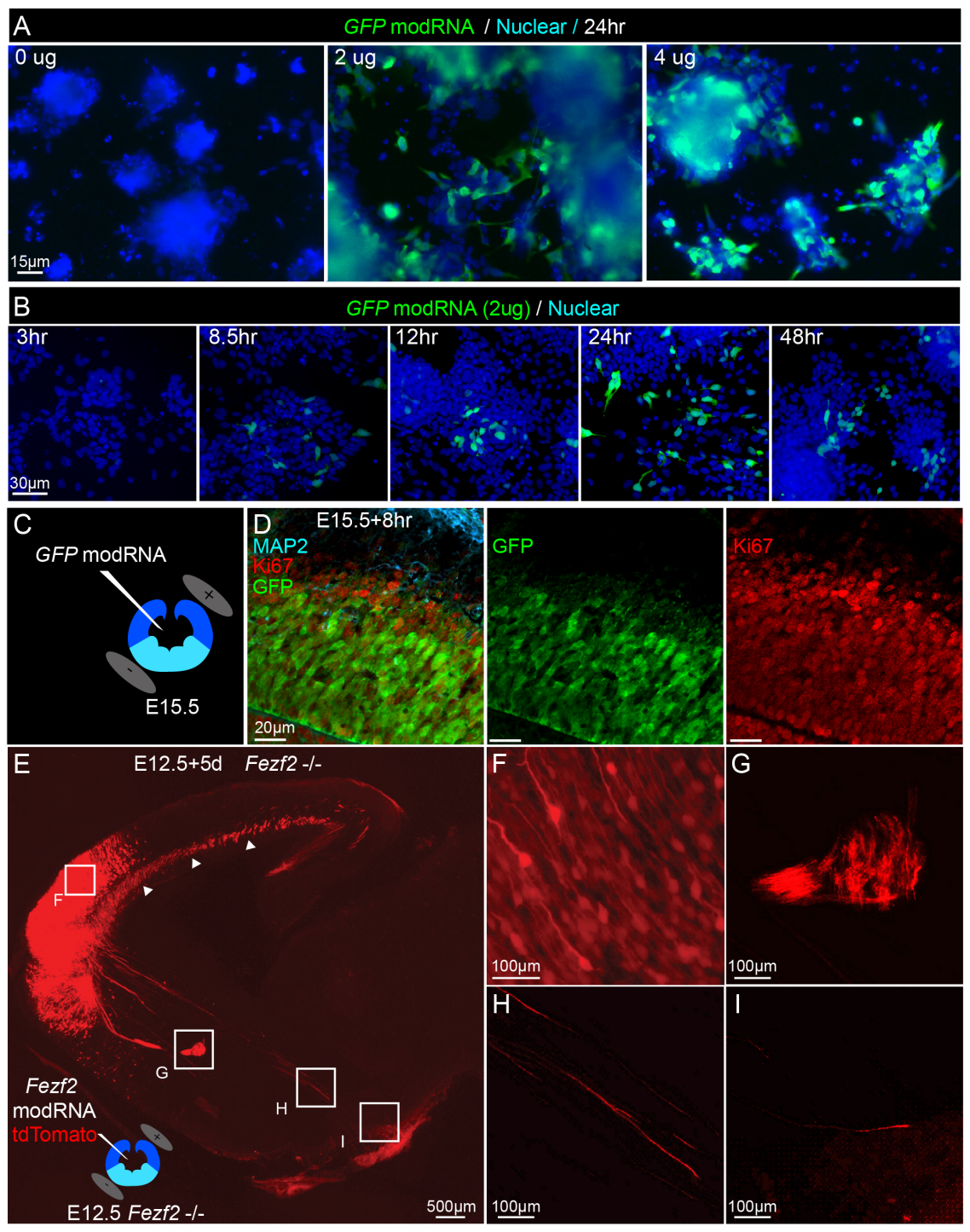


Sadegh et al. 35

905 Figure 1. ModRNA enables temporally controlled, dose-dependent protein

906

907

908

909

910

911

912

913

914

915

916

917

918

919

920

921

922

923

924

925

926

expression in cultured mES-derived populations, and in vivo. (A) GFP modRNA expression is dose-dependent. Native GFP expression is detected in $25-50 \%$ of cells after 24hrs; the intensity of expression increases over the range of $0,2,4$ ug modRNA transfection. (B) GFP modRNA expression is time-dependent over 48hrs. (C) GFP modRNA is injected into the lateral ventricles (coronal cross-section of mouse embryo forebrain is shown), and is directionally electroporated into the dorsal forebrain, or pallium (positive paddle above dark blue colored tissue). (D) Following GFP modRNA in utero electroporation, GFP (green) is expressed after eight hours, and is restricted to Ki67expressing progenitors (red) of the pallium, not in more superficially located post-mitotic neurons, which express MAP2 (blue). (E) Sagittal section of an E17.5 Fezf2-null mouse following E12.5 in utero electroporation of Fezf2 modRNA (0.8 ug/uL) and tdTomato plasmid (1 ug/uL) shows targeted tdTomato fluorescence appropriately restricted to the rostral pallium. (F) Higher magnification image showing tdTomato expression in the cortical plate. (G) tdTomato+ axons project across the cerebral commissures, including anterior commissure (depicted) and corpus callosum in (arrowheads in E). $(H)$ Several tdTomato+ axons project caudal to the thalamus, indicating partial genetic rescue of E12.5 SCPN, which do not exist at all in Fezf2 null mice and can only be generated by the in utero rescue (Molyneaux et al., 2005). (I) A smaller subset of these tdTomato+ axons reach the cerebral peduncle $(\mathrm{N}=3)$, confirming that they are SCPN. 
bioRxiv preprint doi: https://doi.org/10.1101/2020.08.13.242230; this version posted August 13, 2020. The copyright holder for this preprint (which was not certified by peer review) is the author/funder, who has granted bioRxiv a license to display the preprint in perpetuity. It is made available under aCC-BY-NC-ND 4.0 International license.

\begin{tabular}{|c|c|c|c|}
\hline \multicolumn{4}{|c|}{ High Content Small Molecule Screening Identifies SIRT1 } \\
\hline$A$ & DIV15 & DIV19 & SCPN Subtype \\
\hline & $\begin{array}{c}\text { mES cell small molecule } \\
\text { differentiation library added } \\
\text { begins to } \mathrm{mES} \text {-derived }\end{array}$ & $\begin{array}{l}\text { Fezf2 Immuno- } \\
\text { modRNA cytochemistry, } \\
\text { transfection automated }\end{array}$ & $\begin{array}{l}\text { Identity Refinement Ratio: } \\
\text { CTIP2 }^{+} \text {SATB2 }{ }^{-} \text {cell count }\end{array}$ \\
\hline & $\begin{array}{l}\text { pallial-like } \\
\text { progenitors }\end{array}$ & quantification & CTIP2 $^{+}$SATB2 $^{+}$cell count \\
\hline
\end{tabular}

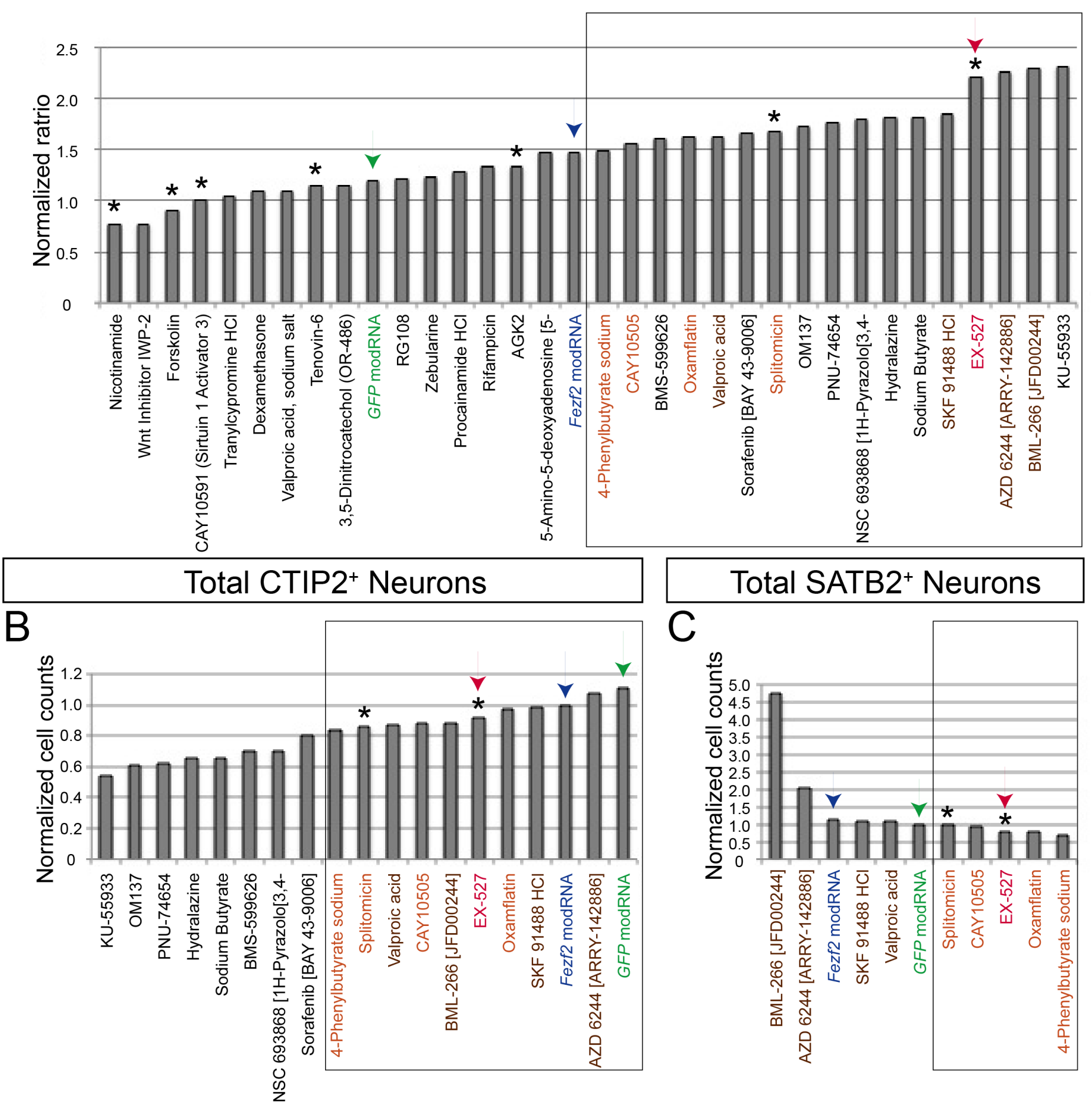


Sadegh et al. 37

928 Figure 2. High-content small molecule screen of SCPN/CSN molecular refinement by mES-derived neurons identifies candidate small molecule regulators,

930 including the SIRT1 inhibitor EX-527.

931 (A) Each well of a 96-well plate containing ES-derived neurons at 15 days in vitro (DIV)

932 was incubated with a distinct small molecule from the library (Figure S3B) for 96hrs,

933 followed by transfection with GFP or Fezf2 modRNA, incubated for an additional 48hrs,

934 and then analyzed at 21 DIV. Distinct small molecules enhanced, inhibited, or did not

935 substantially alter Fezf2-mediated SCPN subtype refinement, as indicated by the ratio

936 of CTIP2(+)/SATB2(-) neurons to CTIP2(+)/SATB2(+) neurons. The ratios are

937 normalized to the untreated condition.

938 (B) Some candidate small molecules, from the box marked in (A), increase the number

939 of CTIP2-expressing neurons relative to Fezf2 induction alone. The ratios are

940 normalized to the Fezf2 modRNA condition.

941 (C) A subset of candidate small molecules, from the box marked in (B), decrease the

942 number of SATB2-expressing neurons relative to Fezf2 induction alone; these include

943 the SIRT1 inhibitor EX-527. Asterisks indicate small molecules that modify HDAC Class

944 III (Sirtuin). Black arrowheads indicate GFP and Fezf2 transfection conditions, for

945 comparison. The red arrowhead indicates EX-527, a relatively specific SIRT1 inhibitor.

946 The ratios are normalized to the GFP modRNA condition.

947 Data from this first-level screen experiment $(\mathrm{N}=1)$ represent approximately 1,000 cells 948 per condition, from 40 randomly sampled fields at $20 x$ magnification. 
bioRxiv preprint doi: https://doi.org/10.1101/2020.08.13.242230; this version posted August 13, 2020. The copyright holder for this preprint (which was not certified by peer review) is the author/funder, who has granted bioRxiv a license to display the preprint in perpetuity. It is made available under aCC-BY-NC-ND 4.0 International license.

A
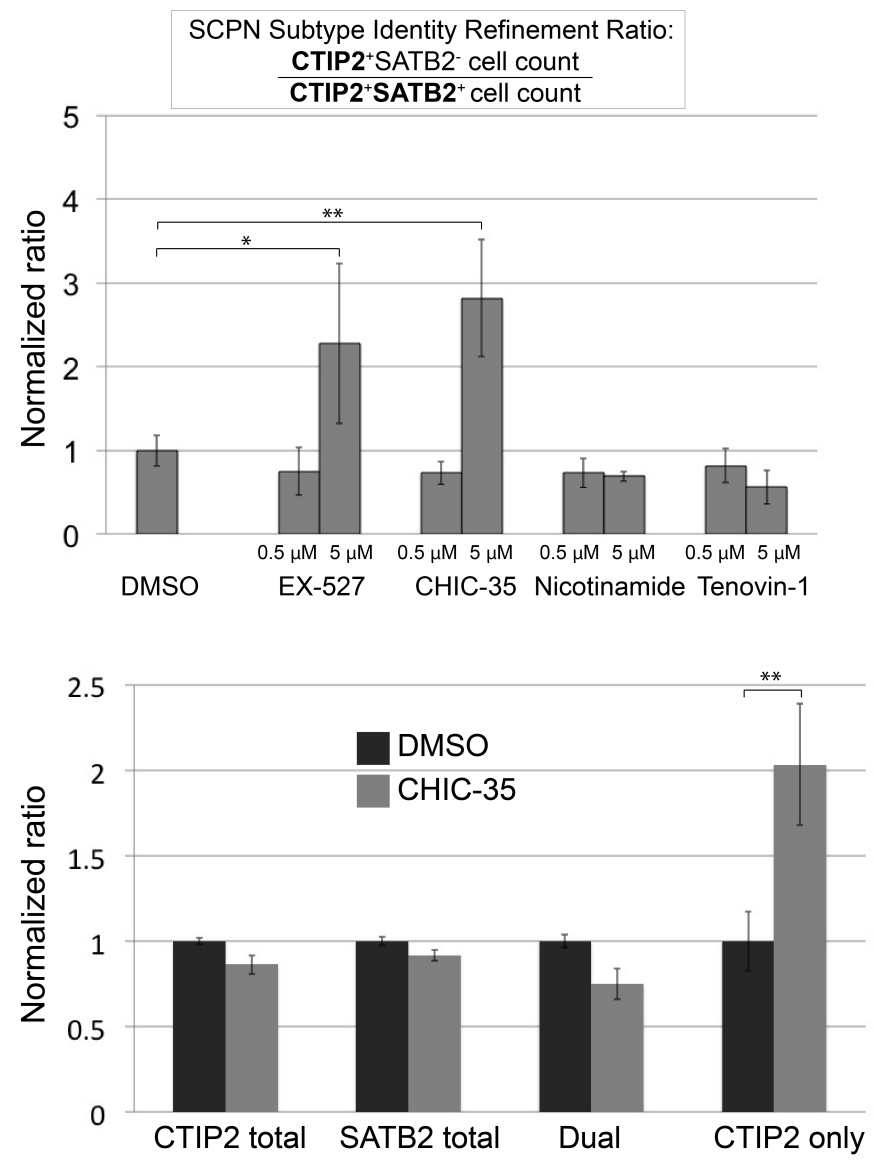

B

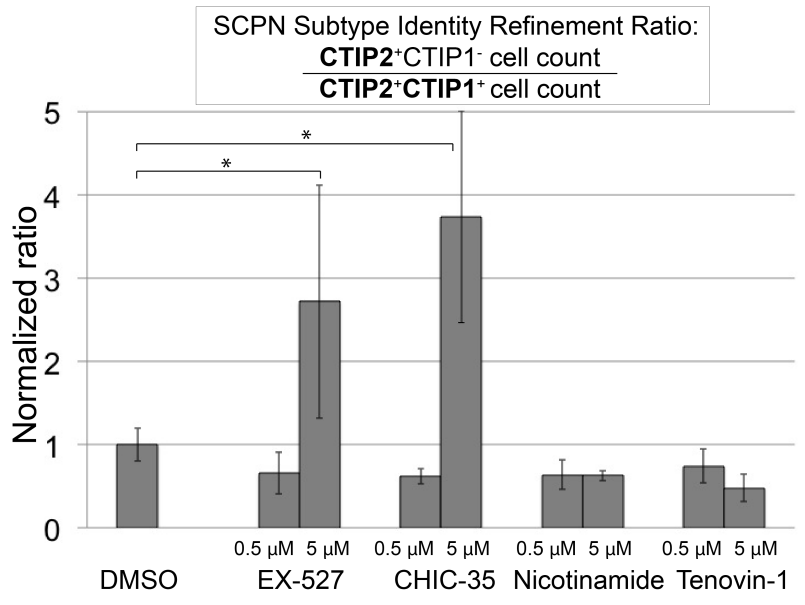

D

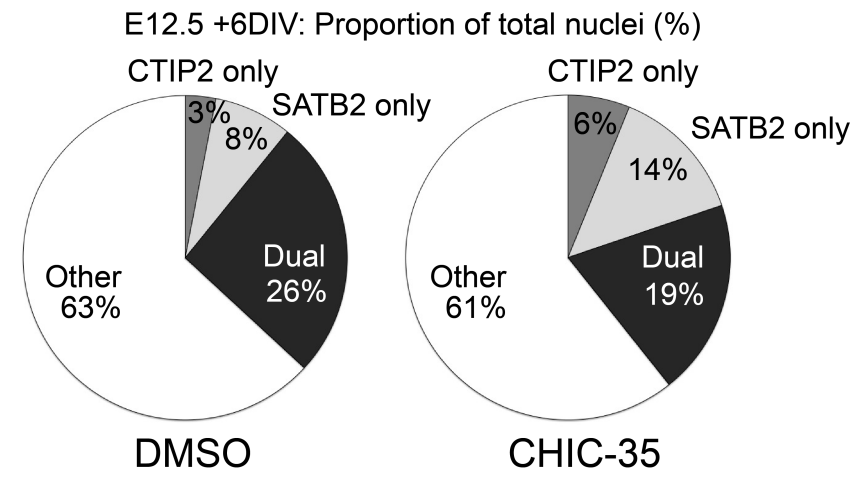


Sadegh et al. 39

952 Figure 3. SIRT1 inhibition in dissociated E12.5 neocortical neurons enhances

953 SCPN/CSN subtype refinement, increasing the number of CTIP2-expressing

954 neurons at the expense of CTIP2/SATB2 dual expressing neurons. (A) EX-527 and

955 a more specific SIRT1 inhibitor, CHIC-35, increase CTIP2/SATB2 subtype distinction

956 relative to DMSO-only controls $(0.5 \mu \mathrm{M}$ and $5 \mu \mathrm{M})$. (B) EX-527 and CHIC-35 also trend

957 toward CTIP2/CTIP1 subtype distinction. (C) Importantly, while the proportions of total

958 CTIP2- and total SATB2-expressing neurons do not change relative to DMSO control

959 following CHIC-35 SIRT1 inhibition, the relative proportion of CTIP2/SATB2 dual

960 expressing neurons decreases. In important contrast, the relative proportion of more

961 fully distinguished CTIP2(+)/SATB2(-) neurons (reflecting SCPN/CSN) increases.

962 (D) Pie chart schematics show the relative proportions of total nuclei of CTIP2+-only

963 neurons, SATB2+-only neurons, CTIP2+/SATB2+ dual expressing neurons, and

964 unlabeled cells derived from E12.5 neocortical cells in CHIC-35 SIRT1 inhibition

965 treatment conditions versus DMSO control. Data are presented as mean +/- s.e.m.

$966(\mathrm{~N}=3 ;>10,000$ nuclei screened per condition from 60 randomly sampled fields at $20 \mathrm{x}$

967 magnification) ${ }^{*} \mathrm{P}<0.05 ;{ }^{* *} \mathrm{P}<0.01$ (unpaired t-test). 
bioRxiv preprint doi: https://doi.org/10.1101/2020.08.13.242230; this version posted August 13, 2020. The copyright holder for this preprint

(which was not certified by peer review) is the author/funder, who has granted bioRxiv a license to display the preprint in perpetuity. It is made available under aCC-BY-NC-ND 4.0 International license.
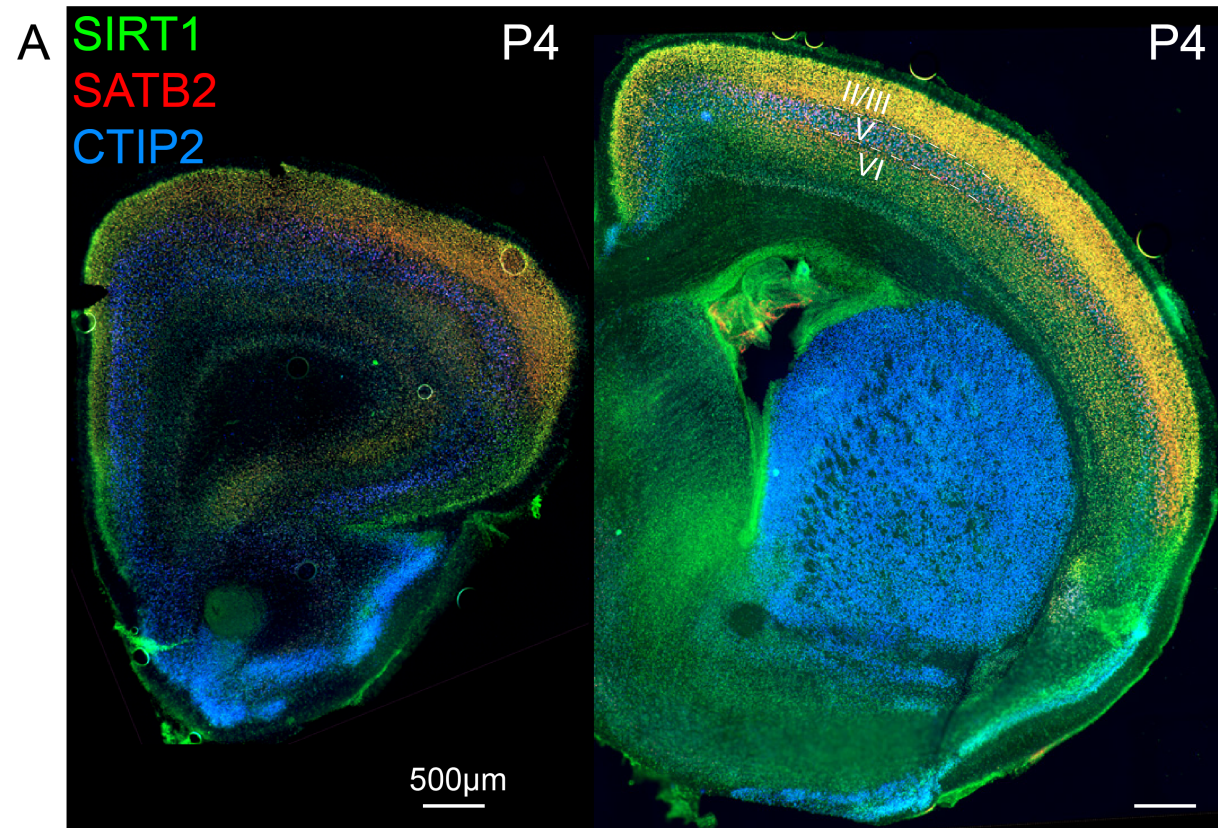

P4

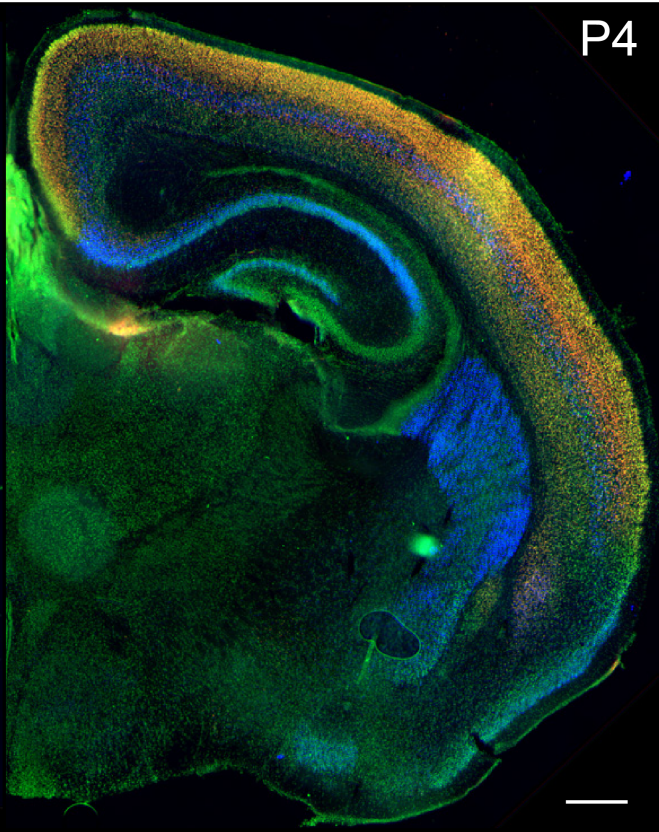

B

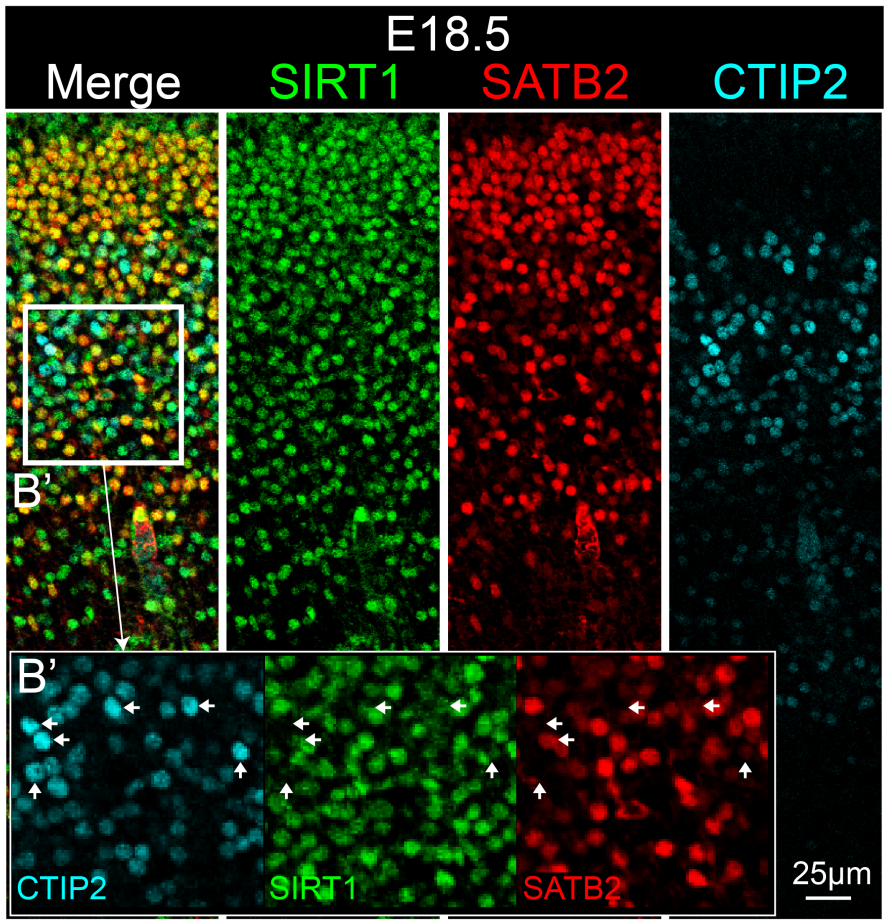

C
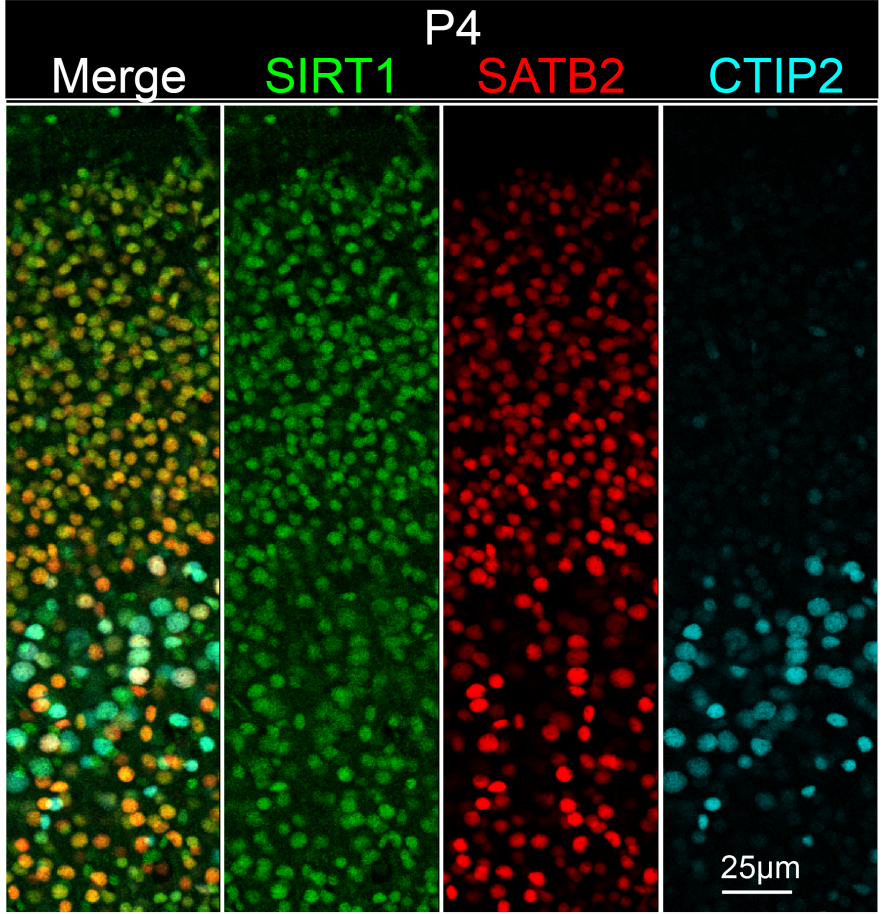
Sadegh et al. 41

969 Figure 4. SIRT1 is differentially expressed by CPN and SCPN/CSN in vivo. (A) At P4,

970 immunocytochemical labeling indicates that SIRT1 is expressed along the entire rostral-

971 caudal extent of the neocortex, in layers II/III, VI, and subplate (50 $\mu \mathrm{m}$ coronal section,

972 wide-field fluorescence imaging). (B) At E18.5, SIRT1 expression in deep layers of motor

973 cortex is predominantly restricted to SATB2-expressing neurons, and is absent or

974 expressed at quite low levels by CTIP2-expressing neurons (50 $\mu \mathrm{m}$ coronal section,

975 confocal fluorescence imaging). (C) At P4, SIRT1 expression in deep layers of motor

976 cortex is almost completely restricted to SATB2-expressing neurons (50 $\mu \mathrm{m}$ coronal

977 section, confocal fluorescence imaging). 
bioRxiv preprint doi: https://doi.org/10.1101/2020.08.13.242230; this version posted August 13, 2020. The copyright holder for this preprint (which was not certified by peer review) is the author/funder, who has granted bioRxiv a license to display the preprint in perpetuity. It is made available under aCC-BY-NC-ND 4.0 International license.

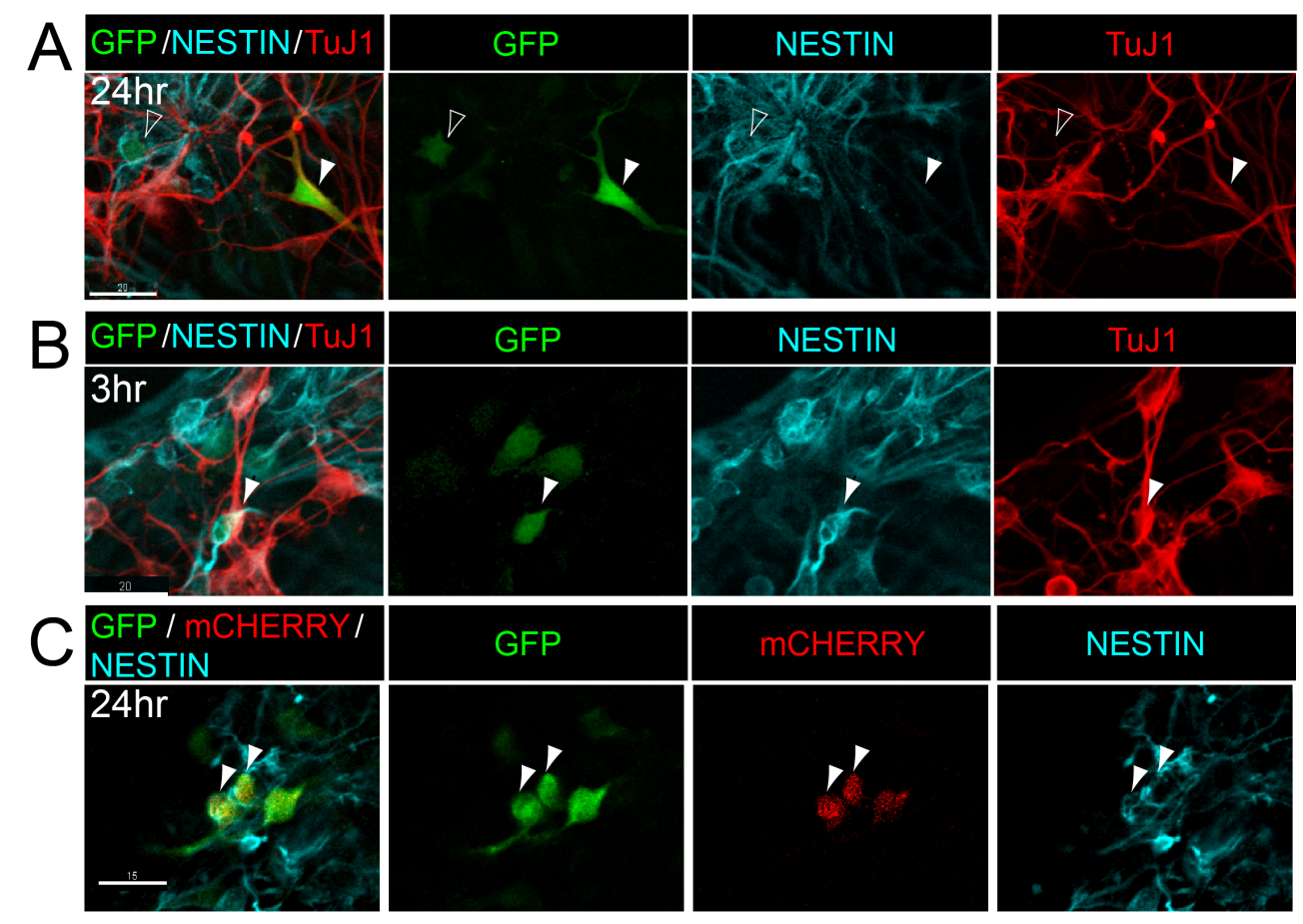


979 Figure S1. modRNA transfection is not biased to a specific neural population. (A)

980 At 24 hours, GFP modRNA transfected mES-derived neocortical-like cells express GFP

981 within progenitors (NESTIN-expressing, empty arrows), immature neurons (TuJ1-

982 expressing, filled arrows), and other cells. (B) GFP is expressed by NESTIN-positive

983 mES-derived cells as early as three hours following transfection with GFP modRNA. (C)

$984 m$ Cherry and GFP modRNA are co-expressed by the same mES-derived cells 24 hours

985 following transfection (native fluorescence). 


\section{DIV mES following modRNA transfection}

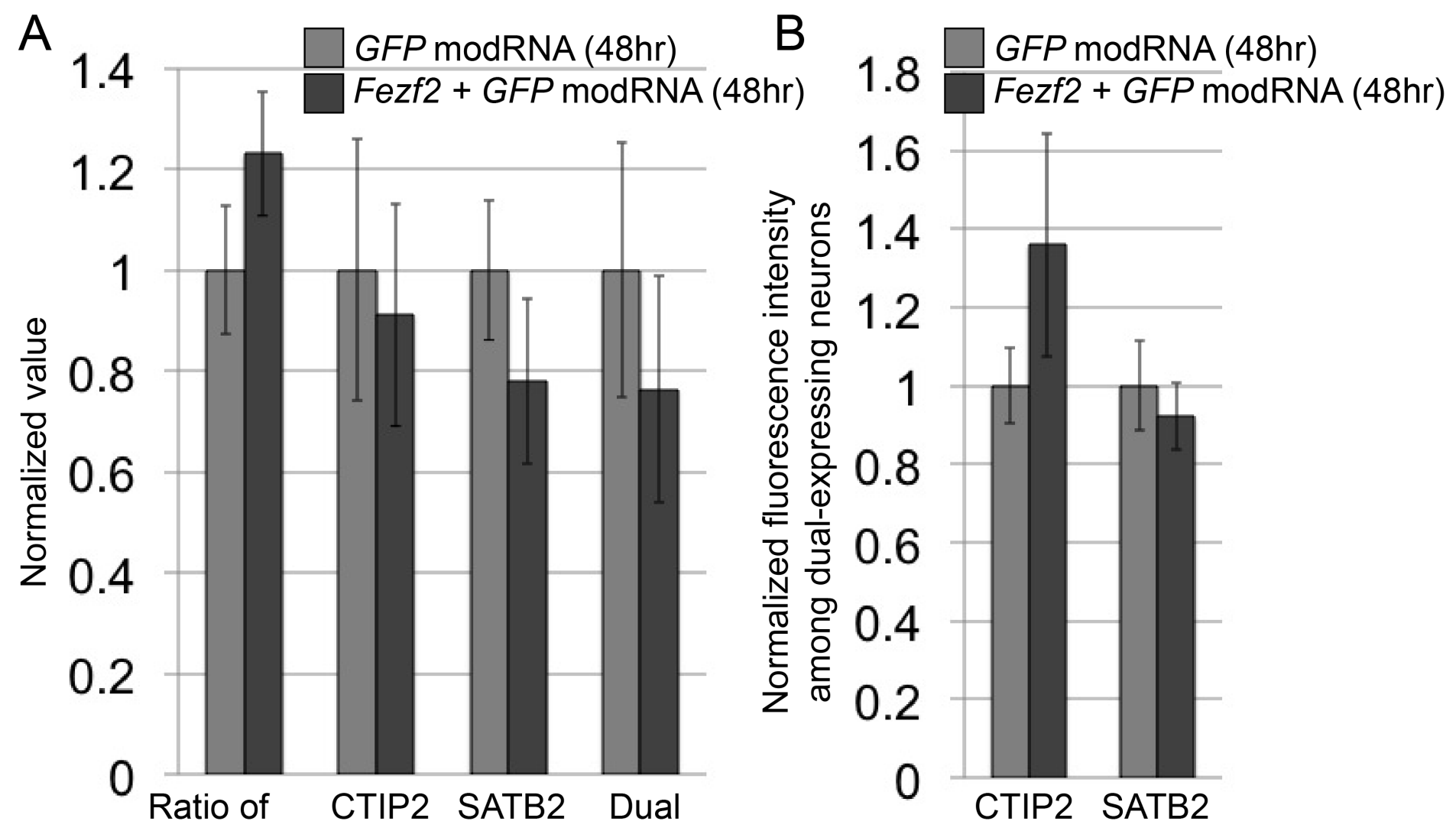

cells expressing total total total

CTIP2-only counts counts counts vs Dual 


\section{Figure S2. Fezf2 induction in ES-derived neurons does not on its own}

988 significantly increase subtype distinction. (A) At 21 days in vitro (DIV), the ratio of

989 CTIP2+/SATB2- neurons to CTIP2+/SATB2+ dual expressing neurons is not statistically

990 significantly increased 48hrs after Fezf2 and GFP modRNA co-transfection (dark grey)

991 relative to GFP modRNA transfection alone (light gray) (though a trend suggests

992 potentially modest increase of approximately $20 \%$ ). The total number of CTIP2-

993 expressing neurons is largely unaffected, as is the number of total SATB2-expressing

994 and CTIP2+/SATB2+ dual expressing neurons (though the latter two display non-

995 statistically significant trends toward decrease in number). (B) The intensity of CTIP2

996 expression within Fezf2, GFP modRNA co-transfected neurons increases relative to

997 GFP modRNA controls. Data are presented as mean +/- s.e.m. (N=3; approximately

9985,000 cells per condition, from 40 randomly sampled fields at $20 x$ magnification). 
bioRxiv preprint doi: https://doi.org/10.1101/2020.08.13.242230; this version posted August 13,2020 . The copyright holder for this preprint (which was not certified by peer review) is the author/funder, who has granted bioRxiv a license to display the preprint in perpetuity. It is made available under aCC-BY-NC-ND 4.0 International license.
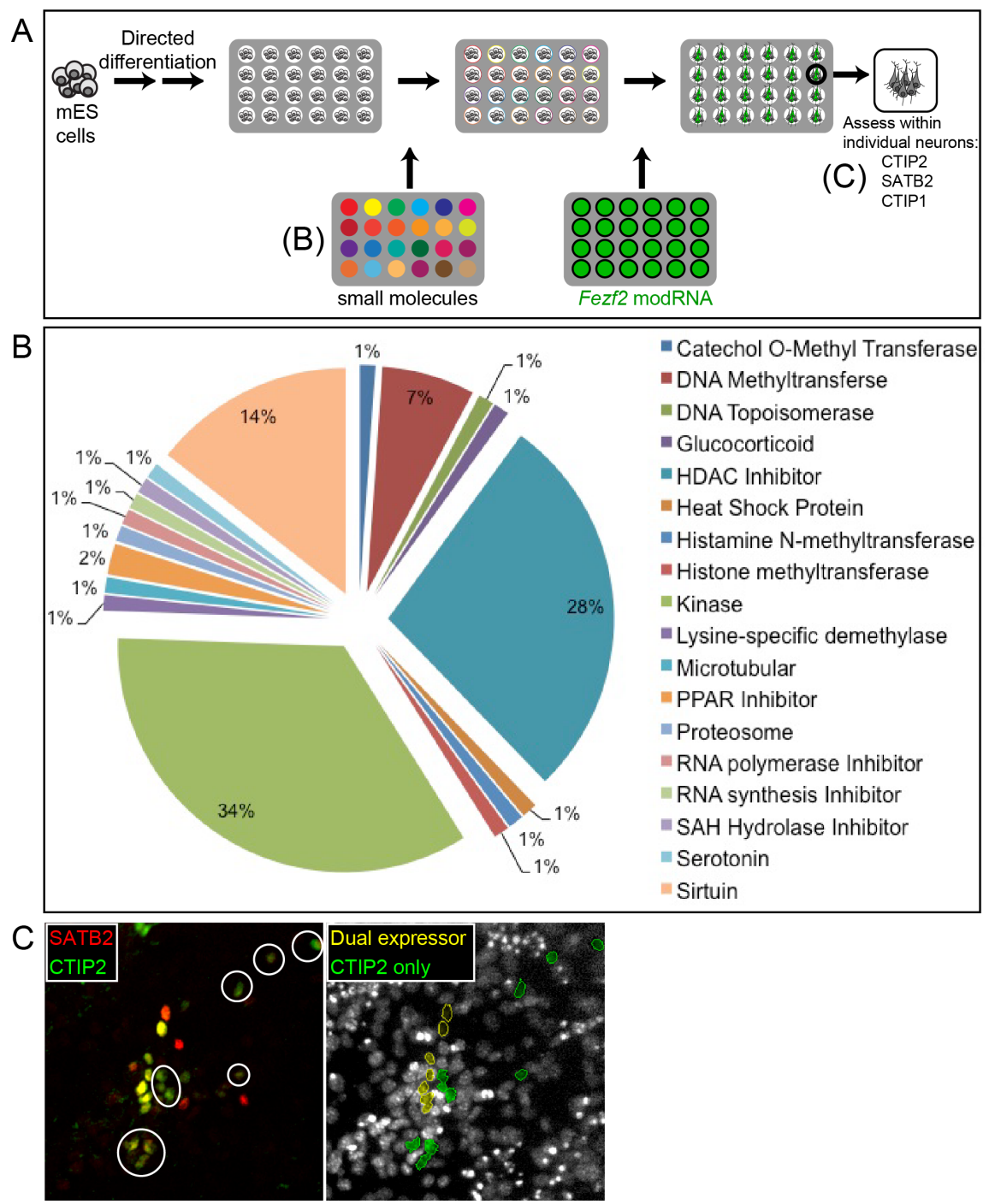
1000 Figure S3. Design of high throughput small molecule screening protocol to 1001 identify potential regulators of subtype refinement within cortical-like neurons.

1002 (A) Schematic of screening strategy in 96-well plates. Monolayer mES differentiation to 1003 telencephalic progenitors is followed by the addition of a custom small molecule library; 1004 the composition of this library is described in (B). After small molecule incubation for six 1005 days, each well is transfected with Fezf2 modRNA. Two days later, cells are fixed and 1006 immunolabeled for CTIP2, SATB2, and CTIP1. Automated imaging and fluorescence 1007 intensity thresholding algorithms distinguish and count neurons; an example of this is 1008 shown in (C).

1009 (B) The composition of a custom set of 80 chemicals regulating histone deacetylases, 1010 methyltransferases, and kinases is depicted in this pie chart.

1011 (C) Automated imaging and counting algorithms identify CTIP2 and SATB2 expression 1012 levels. Manually determined thresholds distinguish CTIP2+/SATB2- neurons (pseudo1013 colored green) from dual expressing CTIP2+/SATB2+ neurons (pseudo-colored yellow). 
E12.5 neocortical neurons

\section{Ratio: [CTIP2 only] to [CTIP2/SATB2 dual]}

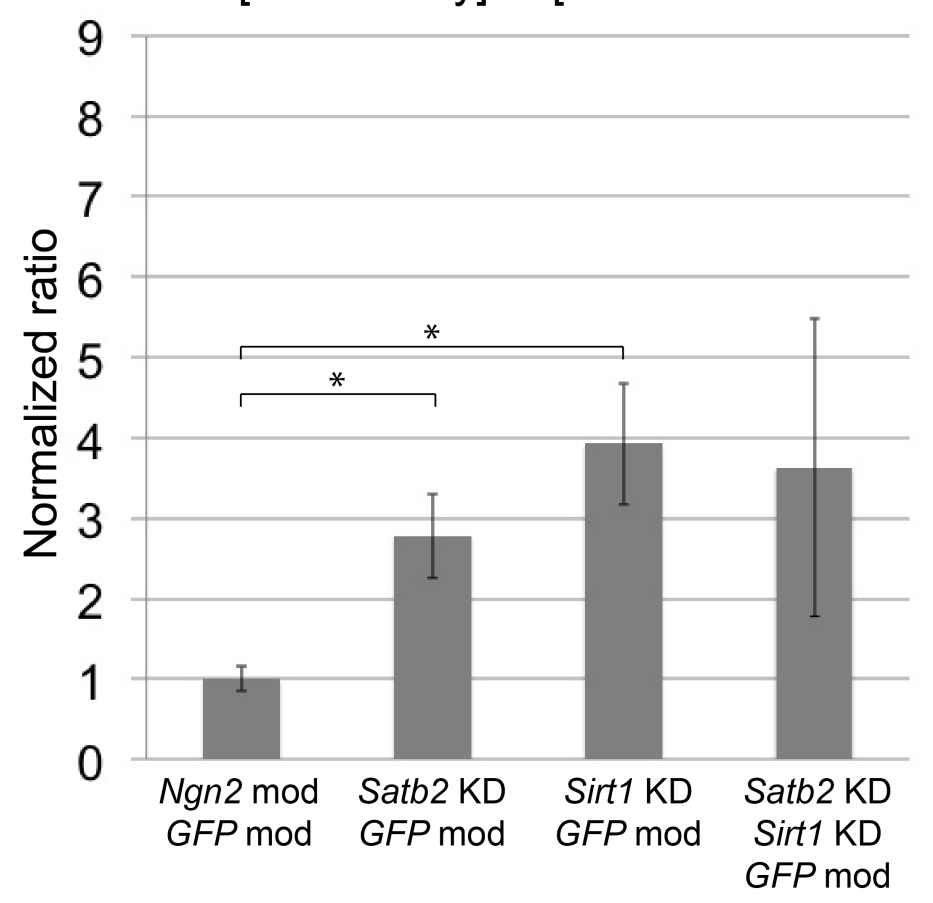

E12.5 neocortical neurons

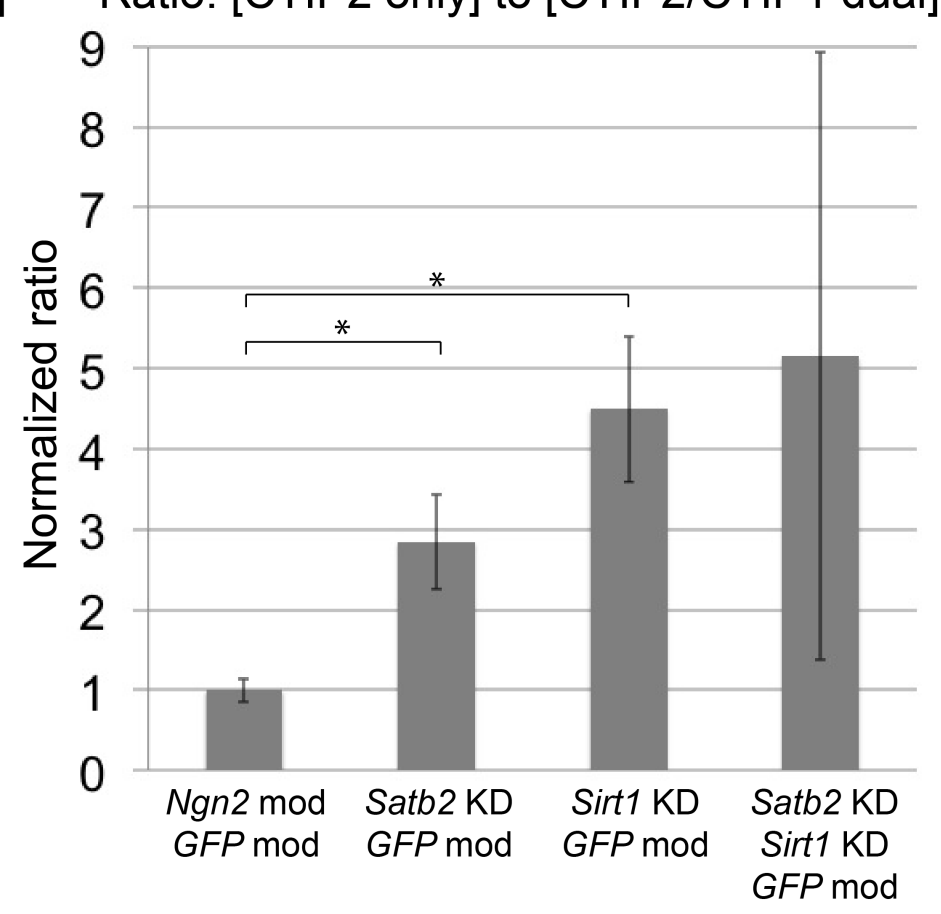


1015 Figure S4. siRNA knockdown of Sirt1 recapitulates the effect of small molecule

1016 inhibition of SIRT1. (A) CTIP2/SATB2 refinement increases with Sirt1 knockdown (KD)

1017 in primary dissociated E12.5 neurons co-transfected with GFP modRNA, as compared

1018 to alternate conditions (co-transfection of Ngn2 and GFP modRNA, or co-transfection of

1019 Satb2 siRNA with GFP modRNA). (B) Consistent with multiple molecular refinements

1020 during neocortical projection neuron subtype distinction, CTIP2/CTIP1 refinement also

1021 increases with Sirt1 knockdown. Data are presented as mean +/- s.e.m. $(N=3 ;>10,000$

1022 nuclei screened per condition, from 60 randomly sampled fields at 20x magnification).

$1023{ }^{*} \mathrm{P}<0.05$ (unpaired t-test). 
bioRxiv preprint doi: https://doi.org/10.1101/2020.08.13.242230; this version posted August 13,2020 . The copyright holder for this preprint (which was not certified by peer review) is the author/funder, who has granted bioRxiv a license to display the preprint in perpetuity. It is made available under aCC-BY-NC-ND 4.0 International license.
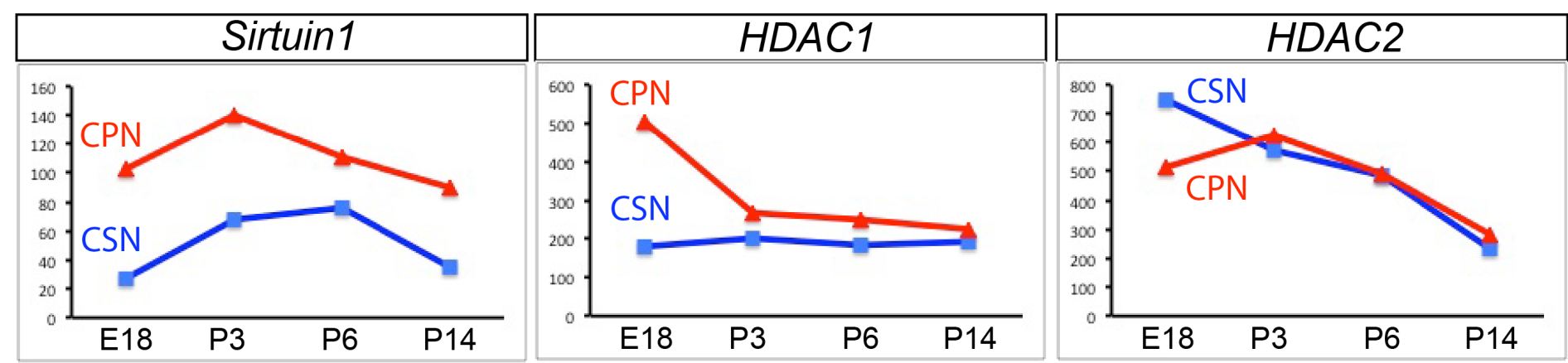
1025 Figure S5. Sirt1 mRNA expression is CPN-specific in the neocortex at late

1026 embryonic and postnatal ages. (A) Sirt1 mRNA expression is higher by CPN (red

1027 lines) than by CSN (blue lines) at E18.5, P3, P6, and P14; these populations were

1028 retrogradely labeled and purified by fluorescence-activated cell sorting (FACS) for

1029 comparative gene expression analysis at each time-point (data from Arlotta et al.,

1030 2005). (B) Other HDACs (e.g., HDAC1 and HDAC2) are not differentially expressed at

1031 all ages, using the same microarray data. 